\title{
Review Article \\ Review of Energy Harvesters Utilizing Bridge Vibrations
}

\author{
Farid Ullah Khan and Iftikhar Ahmad \\ Institute of Mechatronics Engineering, University of Engineering and Technology, Peshawar 25000, Pakistan \\ Correspondence should be addressed to Farid Ullah Khan; dr_farid_khan@uetpeshawar.edu.pk \\ Received 20 April 2015; Revised 3 September 2015; Accepted 13 September 2015 \\ Academic Editor: Jeong-Hoi Koo
}

Copyright ( 2016 F. U. Khan and I. Ahmad. This is an open access article distributed under the Creative Commons Attribution License, which permits unrestricted use, distribution, and reproduction in any medium, provided the original work is properly cited.

\begin{abstract}
For health monitoring of bridges, wireless acceleration sensor nodes (WASNs) are normally used. In bridge environment, several forms of energy are available for operating WASNs that include wind, solar, acoustic, and vibration energy. However, only bridge vibration has the tendency to be utilized for embedded WASNs application in bridge structures. This paper reports on the recent advancements in the area of vibration energy harvesters (VEHs) utilizing bridge oscillations. The bridge vibration is narrowband (1 to $40 \mathrm{~Hz}$ ) with low acceleration levels $(0.01$ to $3.8 \mathrm{~g}$ ). For utilization of bridge vibration, electromagnetic based vibration energy harvesters (EM-VEHs) and piezoelectric based vibration energy harvesters (PE-VEHs) have been developed. The power generation of the reported EM-VEHs is in the range from 0.7 to $1450000 \mu \mathrm{W}$. However, the power production by the developed PE-VEHs ranges from 0.6 to $7700 \mu \mathrm{W}$. The overall size of most of the bridge VEHs is quite comparable and is in mesoscale. The resonant frequencies of EM-VEHs are on the lower side $(0.13$ to $27 \mathrm{~Hz}$ ) in comparison to PE-VEHs (1 to $120 \mathrm{~Hz}$ ). The power densities reported for these bridge VEHs range from 0.01 to $9539.5 \mu \mathrm{W} / \mathrm{cm}^{3}$ and are quite enough to operate most of the commercial WASNs.
\end{abstract}

\section{Introduction}

Wireless sensor nodes (WSNs) are used for sensing and monitoring of several environmental characteristics, such as pressure, humidity, temperature, sound pressure levels, vehicles tracking, vibration levels, lighting information, the absence or presence of material goods, and strain levels in mechanical components $[1,2]$. The architecture of WSN is shown in Figure 1. A WSN consists of various components [3], like microsensors, signal processing unit, power management unit, microcontroller unit, built-in memory, analog to digital converter (ADC), transmitter, receiver, and a super capacitor. Sensor converts the physical signal, such as pressure, temperature, humidity, or vibration, into a respective electrical signal. The transmitter and receiver are used for transmitting and receiving the information data between WSN and the operator. Memory unit enables on-board data storage. Microcontroller controls the overall performance and operation of different components present on board. Power management circuit distributes and manages the power to the WSN components. A battery or a super capacitor is used as the power source in the WSN [4]. Most of the commercial WSNs operate on batteries; however, the restricted life of batteries limits the performance and application of WSNs. For a device with $100 \mu \mathrm{W}$ power consumption, a lithium battery of $1 \mathrm{~cm}^{3}$ volume can be used only for one-year operation [5]. Replacement or recharging of batteries is feasible for small scale WSN networks; however, for a gigantic WSN network which is spread over enormous area, the replacement or recharging of batteries is completely impossible. Moreover, for WSNs placed in remote, hazardous, and inaccessible locations, the replacement of batteries can be inconvenient and costly [6]. WSNs have enormous applications in almost every field of life, such as in industrial machines, civil infrastructures, military equipment, traffic control, healthcare accessories, agricultural equipment, and domestic and office appliances.

Moreover, for the health monitoring of the bridge structures $[7,8]$, wireless acceleration sensor nodes (WASNs) are utilized to monitor the vibrations induced in the bridges due to moving vehicles and high velocity winds. Because of the rapid advancements in ultra-low power microaccelerometers, microprocessors, microcontrollers, and signal processing circuits, the power requirements of the WASNs have enormously reduced to few $\mathrm{mW}$. Various types of WASNs are developed and commercially available. Some of 
TABLE 1: Summary of commercially available wireless sensors nodes.

\begin{tabular}{|c|c|c|c|c|c|c|}
\hline Sensor type & Manufacturer & Model & Sensing range & $\begin{array}{c}\text { Operating } \\
\text { voltage }(\mathrm{V}) \\
\end{array}$ & $\begin{array}{c}\text { Operating } \\
\text { current }(\mathrm{mA})\end{array}$ & $\begin{array}{l}\begin{array}{l}\text { Power } \\
(\mathrm{mW})\end{array} \\
\end{array}$ \\
\hline \multirow{7}{*}{ Acceleration } & Freescale semiconductor & MMA7260QT & $\pm 1.5 / 2 / 4 / 6 \mathrm{~g}$ & 3.3 & 0.5 & $1.65^{\mathrm{a}}$ \\
\hline & STMicroelectronics & LSI302ALB & $\pm 2 \mathrm{~g}$ & 3.6 & $\mathrm{n} . \mathrm{r}^{\mathrm{b}}$ & 2 \\
\hline & Analog devices & ADXL210JQC & $\pm 10 \mathrm{~g}$ & 4.5 & 0.6 & $2.7^{\mathrm{a}}$ \\
\hline & Freescale semiconductor & MMA1270KEG & $\pm 2.5 \mathrm{~g}$ & 5 & 2.1 & $10.5^{\mathrm{a}}$ \\
\hline & MEMSIC & MXD2020E/F & $\pm 1 \mathrm{~g}$ & 3.3 & 4 & $13.2^{\mathrm{a}}$ \\
\hline & $\mathrm{BOSCH}$ & SMB455 & $\pm 70 \mathrm{~g}$ & 3.3 & 8 & $26.4^{\mathrm{a}}$ \\
\hline & Analog devices & ADIS16000 & $\pm 18 \mathrm{~g}$ & 3.3 & 39 & $128^{\mathrm{a}}$ \\
\hline
\end{tabular}

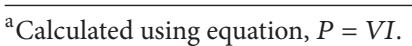

${ }^{b}$ n.r. not reported in the data sheet provided by the manufacturer.

TABLE 2: Summary of bridge vibration data.

\begin{tabular}{|c|c|c|c|c|}
\hline Bridge & Location & $\begin{array}{c}\text { Frequency } \\
(\mathrm{Hz})\end{array}$ & $\begin{array}{c}\text { Acceleration } \\
(\mathrm{g})\end{array}$ & Reference \\
\hline New Carquinez & California & $1-40$ & $0.01-0.102$ & {$[10]$} \\
\hline Komtur & Berlin & $2-2.6$ & $0-0.0061$ & {$[11]$} \\
\hline Ypsilanti & Michigan & $2-30$ & $0.01-0.035$ & {$[12]$} \\
\hline Golden Gate & San Francisco & $0-1.5$ & $0-0.061$ & {$[13]$} \\
\hline RT11 bridge in Potsdam & New York & 3.1 & 0.38 & {$[14]$} \\
\hline Box girder bridge & Austin & $1-15$ & 0.12 & {$[15]$} \\
\hline 3rd Nongro Bridge & South Korea & 4.1 & 0.025 & {$[16]$} \\
\hline Huanghe Cable-Stayed Bridge & China & $1-2$ & 0.015 & {$[17]$} \\
\hline Seohae Grand Bridge & South Korea & 1 & 0.0125 & {$[18]$} \\
\hline IH-35N over Medina River & Texas & 3.1 & 0.15 & {$[19]$} \\
\hline
\end{tabular}

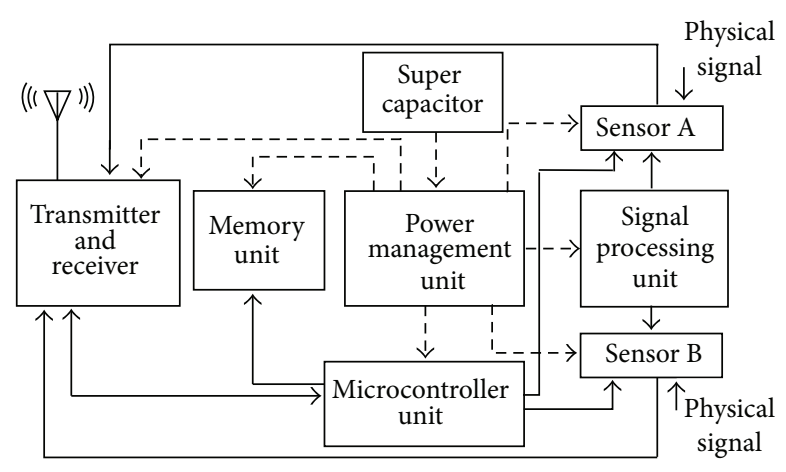

FIGURE 1: Architecture of a wireless sensor node.

the commercial WASNs along with their operating parameters are listed in Table 1 . The values, in Table 1, have been extracted from the WASN data sheet available on the manufacturer's websites and guide manuals.

In Table 1, commercial WASNs require a voltage from 3.3 to $5 \mathrm{~V}$ for their operation; however, the overall range for the current drawn by WASNs during the transmission operation is from 0.5 to $39 \mathrm{~mA}$. Moreover, the power requirements of these WASNs that range from 1.65 to $128 \mathrm{~mW}$ are normally accomplished with batteries.
During condition monitoring of bridges the vibration levels are continuously measured. Bridge health monitoring (BHM) needs continuous operation of WASNs throughout the life of the bridge. In WASNs, batteries as a power source restrict these to be embedded within the bridge structure. The sole solution for powering the embedded WASNs is energy harvesting. For conversion of WASNs into autonomous acceleration sensor nodes (AASNs), the power need of these WASNs (overall power range from 1.65 to $128 \mathrm{~mW}$ ) is required to be obtained from alternative sources, such as energy harvester. At the bridge, solar, acoustic, wind, and vibration energies are abundantly available; however, only the vibration energy has the tendency to be utilized for embedded WASNs application. Solar and wind energy harvesters are not the best option for WASNs [9], which quite often need to be located outside the bridge structure, such as in places with extremely high light intensities and fast blowing air; as a result, WASNs may also face the same environmental factors problem. Bridge vibration is produced by the vehicular motion and high wind speeds. Normally the bridges oscillation is narrowband random in nature with frequency and acceleration levels on the lower side [10]. Table 2 lists the vibration information of several bridges. In Table 2 the frequency of the bridge vibration varies from $1 \mathrm{~Hz}$ to $40 \mathrm{~Hz}$. The Golden Gate Bridge located at San Francisco, USA, has the lowest frequency $(1.5 \mathrm{~Hz})$; however, the New Carquinez 
TABLE 3: Piezoelectric materials and their properties.

\begin{tabular}{|c|c|c|c|c|c|}
\hline Materials & $\begin{array}{l}\text { Density } \\
\left(\mathrm{g} / \mathrm{cm}^{3}\right)\end{array}$ & $\begin{array}{c}\text { Young's } \\
\text { modulus (GPa) }\end{array}$ & $\begin{array}{c}\text { Curie } \\
\text { temperature }\left({ }^{\circ} \mathrm{C}\right)\end{array}$ & $\begin{array}{c}\text { Dielectric } \\
\text { constant @ } 1 \mathrm{kHz}\end{array}$ & $\begin{array}{c}\text { Dissipation constant } \\
@ 1 \mathrm{kHz}(\%)\end{array}$ \\
\hline Lead titanate & 6.7 & 112.8 & 240 & 270 & 0.9 \\
\hline Lead magnesium niobate (PMN) & 7.85 & 61 & 170 & 5500 & 2.0 \\
\hline Lead Zirconate Titanate (soft) & 7.5 & 63 & 350 & 1725 & 2.0 \\
\hline Lead Zirconate Titanate (hard) & 7.5 & 63 & 320 & 1250 & 0.4 \\
\hline Quartz & 2.6 & 76.5 & 550 & $3.75^{*}$ & \\
\hline Barium titanate & 6.02 & 67 & 120 & 1550 & 0.03 \\
\hline Polyvinylidene difluoride (PVDF) & 1.78 & 8.3 & 205 & 12 & \\
\hline Lead Lanthanum Zirconate Titanate & 8 & & 315 & 11262 & \\
\hline Aluminium titanate & 3.4 & 20 & & & \\
\hline Aluminium oxide & 3.95 & 413 & 311 & $11.5^{*}$ & $0.0086^{*}$ \\
\hline Zinc oxide $(\mathrm{ZnO})$ & 5.61 & 147.3 & 430 & & \\
\hline
\end{tabular}

${ }^{*}$ The values are at $1 \mathrm{MHz}$.

Bridge at California, USA, has the highest frequency of $40 \mathrm{~Hz}$. The lowest acceleration level of $0.1 \mathrm{~g}$ is recorded for the New Carquinez Bridge, California, USA. However, $0.15 \mathrm{~g}$, the highest acceleration level, is produced at $\mathrm{IH}-35 \mathrm{~N}$ over Medina River, Texas, USA. The overall frequency and acceleration content in the bridge vibration is in the range of 1 to $40 \mathrm{~Hz}$ and 0.01 to $3.79 \mathrm{~g}$, respectively. These bridge vibration levels can be utilized to generate power with vibration-based energy harvesters. For converting WASN into autonomous and selfpowered system, it can be integrated with a vibration-based energy harvester. The vibration-based energy harvester will transform the ambient bridge vibrations that are available in the vicinity of the WASN into electrical energy which can then be utilized for the operation of the entire onboard components in WASN.

\section{Vibration-Based Energy Harvester}

Vibration-based energy harvester (VEH) converts the ambient mechanical vibration into electrical energy. Most of the developed VEHs are resonators and hence produced maximum power, when these are operated at the resonant frequency [20]. Nonresonant VEHs [21] are also gaining grounds in recent years. The output response of VEHs completely depends on the nature of vibrations. Under sinusoidal excitation the behavior of $\mathrm{VEH}$ is completely different than the response of the same $\mathrm{VEH}$ when it is subjected to random vibrations. Various types of VEHs have been developed and reported in the literature. Based on the transduction mechanism, the VEHs are classified as piezoelectric [22], electrostatic [23], and electromagnetic [24] energy harvesters.

2.1. Piezoelectric Vibration Energy Harvesters. In piezoelectric vibration energy harvester (PE-VEH), a piezoelectric material is deposited on a suspended structure, such as a beam or membrane. Due to the vibration, as the suspended structure oscillates, the piezoelectric material is subjected to deformation or strain. As a result of this strain or deformation polarization occurs across the piezoelectric material and voltage is induced [22]. Normally, in PE-VEHs, electrodes are used to carry away the induced charge to the load. For $\mathrm{PE}-\mathrm{VEH}$, a number of piezoelectric materials are available, the detail of which is listed in Table 3. In PE-VEH, the selection of particular piezoelectric material depends on a number of criterions, such as dielectric constant, Curie temperature, or modulus of elasticity of the material. For example, for high acceleration vibrations, the piezoelectric materials (Lead titanate and Aluminum oxide) with high value of Young's modulus can be the desirable choice. However, for high temperature applications, Aluminum oxide is the material of choice. Lead Lanthanum Zirconate Titanate has a very high value of dielectric constant and therefore it is expected to perform very well in low acceleration vibration environments. Due to the easiness of in situ fabrication of Lead Zirconate Titanate (PZT) with sol-gel technique and the easy integration of PZT fabrication with the other microfabrication processes, PZT is largely utilized as the transduction material in most of the developed PE-VEHs. Based on the device architecture, the reported PE-VEHs can be classified into cantilever unimorph type PE-VEH [25], cantilever bimorph type PE-VEH [26], and membrane type PE-VEH [27]. Figure 2 shows the schematic diagram of different typical types of PE-VEHs developed in the literature. The unimorph cantilever type PE-VEH consists of a suspension beam (cantilever beam), Figure 2(a), and normally, on top surface of the beam, a piezoelectric material is deposited. However, in bimorph cantilever type PE-VEH, for better performance dual layers of piezoelectric materials are deposited on upper and lower surfaces of the base beam, Figure 2(b). A membrane type PE-VEH shown in Figure 2(c) comprises a membrane. A membrane is fabricated on a cavity and a piezoelectric material layer is pasted either on top or both top and bottom surfaces of the membrane. Electrodes, mostly of either gold or copper, are coated on the piezoelectric layer to collect the charges during the operation of PE-VEH. Moreover, in the harvester a proof mass is used to adjust the resonant frequency of PE-VEH [28]. When the PE-VEH is 


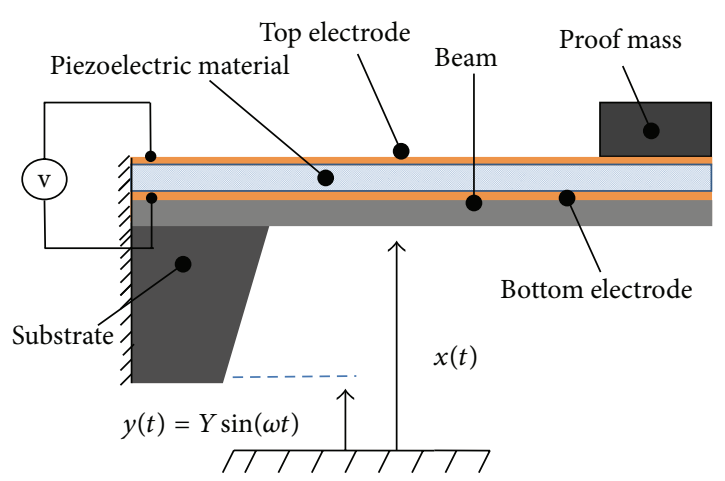

(a)

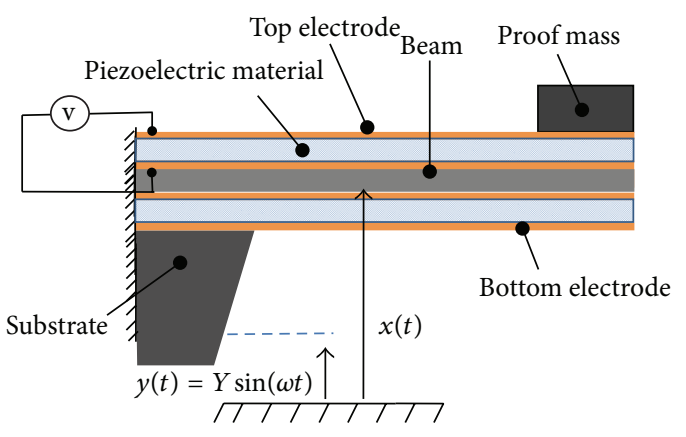

(b)

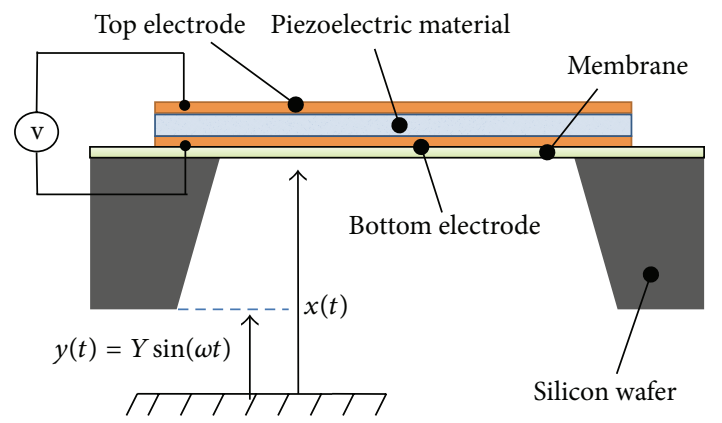

(c)

FIGURE 2: Schematic diagram of various PE-VEHs: (a) unimorph cantilever type PE-VEH, (b) bimorph cantilever type PE-VEH, and (c) membrane type piezoelectric PE-VEH.

subjected to base excitation, the beam or membrane vibrates at a much amplified displacement. The strain developed in the piezoelectric material due to the deflection (vibration) causes the charge to form across the piezoelectric layer.

2.2. Electrostatic Vibration Energy Harvesters. Electrostatic vibration energy harvesters (ES-VEHs) are based on changing capacitance between a fixed and a movable metallic plate. In ES-VEHs, the oppositely charged plates are partly separated by vibration and hence mechanical energy is transformed into electrical energy [20]. The plates are initially kept charged with a voltage source and as the gap or overlap area between the plates changes, the changing capacitance causes increase in the voltage across the plates, thus providing the means for mechanical to electrical energy transduction [20]. Schematic diagrams of different architectures, normally adopted for ES-VEHs, are shown in Figure 3. The ES-VEHs, shown in Figures 3(a) and 3(b), are plate type ES-VEHs. The out-of-plane, gap varying type ES-VEH, Figure 3(a), is comprised of a fixed plate, deposited on a substrate and a movable plate, suspended on top of the fixed plate with the help of fixed-guided beams and anchors. During the operation, when the energy harvester is subjected to base excitation $y(t)$, the movable plate moves perpendicular to the fixed plate and the gap (capacitance) between the plates varies. For in-plane plate type, ES-VEH, the moveable plate is allowed to move in the plane of the harvester and during operation the overlap area between the plates changes. The ES-VEHs shown in Figures 3(c) and 3(d) are normally known as comb type ES-VEHs. In these types of ES-VEHs, there are a number of interdigitated plates (electrodes). The static plates are produced on the substrate; however, the movable plates are the integral part of the shuttle mass, suspended by fixed-guided beams. Both energy harvesters are in-plane harvesters; however, comb type ES-VEH, in Figure 3(c), is a gap varying kind of energy harvester and the one shown in Figure 3(d) is an overlap varying type of ES-VEH.

There are two ways in which ES-VEHs are able to readily create a Coulomb force, a gap closing arrangement operated in a constant charge mode, and a sliding arrangement operated in a constant voltage mode [29]. To permit the time dependent operations (charging and discharging) in the ES-VEH, switching is performed between the energy harvester and the energy extraction circuit (EEC). The operation cycle of a charge constraint ES-VEH is shown in Figures 4 and 6. At its maximum capacitance, the ES-VEH is charged by a battery (line $A B$ in Figure 6(a)). When this initially charged capacitor is detached from the power source (battery) and the EEC, the movement of the harvester's plates reduces the capacitance and increases the voltage across the capacitive plates (line $B C$ ). In the step $B C$, the mechanical motion is actually converted into electrical energy. When point $C$ is reached, the switching connects the harvester to the EEC and the harvester's plates are discharged back to initial position, point $A$, through line $C A$. In Figure 6(a) the area enclosed by the operational cycle of the ES-VEH is actually the amount of energy generation.

If the conductive plates of the ES-VEH that are initially charged and still attached to the voltage source (battery) are relatively moved in a sliding mode of operation, the electrostatic force (voltage) between the plates remains constant. The operation of ES-VEH in a constant voltage mode is shown in Figures 5 and $6(\mathrm{~b})$. The ES-VEH is charged to its maximum capacity along line $A B$, in Figure 6(b). Afterward, the plates are allowed to move horizontally; however, as the battery is still connected to the plates during the motion the capacitance of the harvester decreases (line $B C$ ). Line $B C$ shows the power generation of the harvester, where the mechanical motion is converted to electrical energy. The ES-VEH is disconnected from the battery and connected to the load part of the circuit due to which the charge flows out of the harvester's plate and the voltage drops from $V_{\text {in }}$ to $V_{\text {res }}$ (line $C A$ ). The net area, $A B C A$, in the $Q V$ plot, Figure 6(b), represents the amount of energy generation during one complete cycle of operation. 


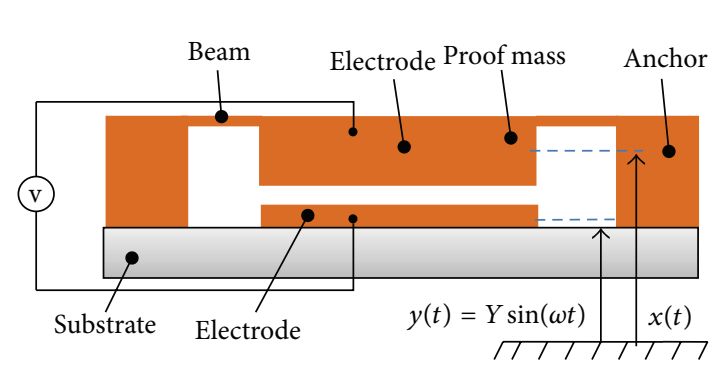

(a)

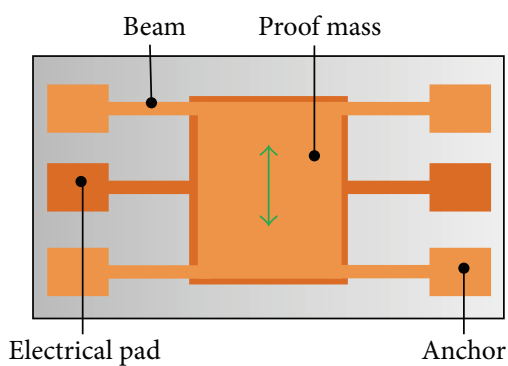

(b)

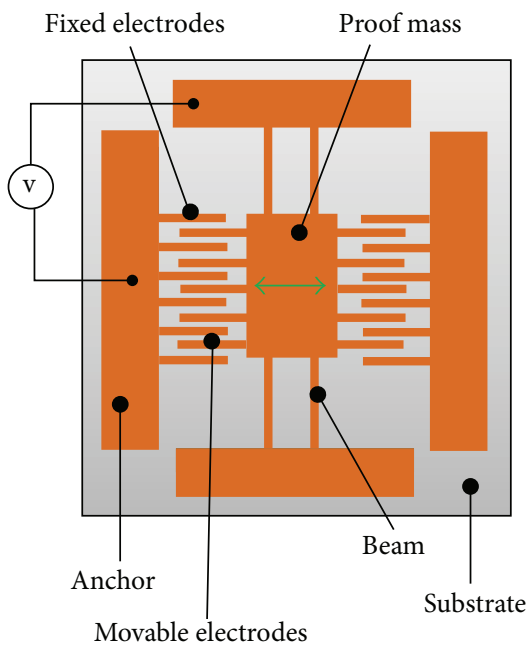

(c)

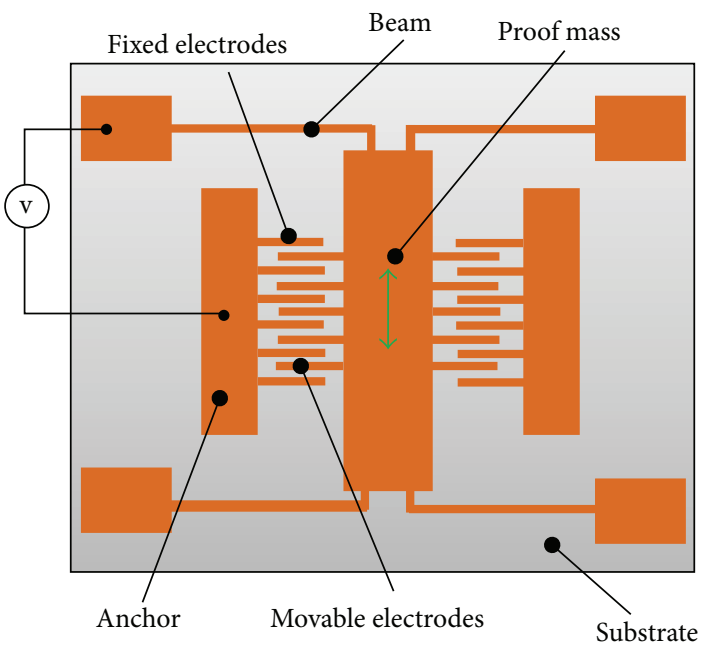

(d)

FIGURE 3: Schematic diagram of ES-VEHs: (a) out-of-plane gap varying type ES-VEH, (b) in-plane, overlap area varying ES-VEH, (c) comb type overlap area varying ES-VEH, and (d) comb type gap varying ES-VEH.

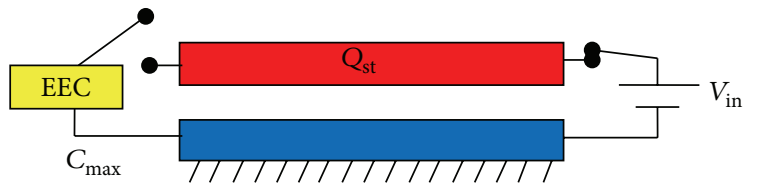

(a)

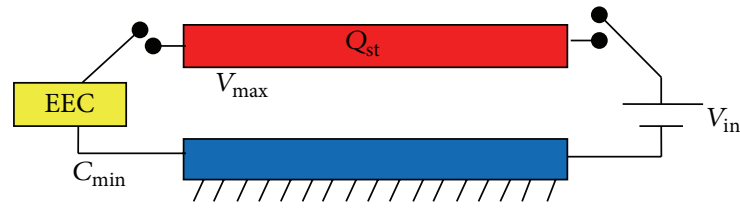

(c)

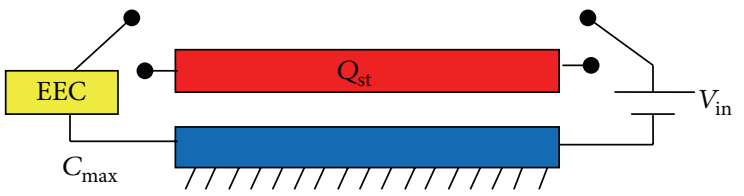

(b)

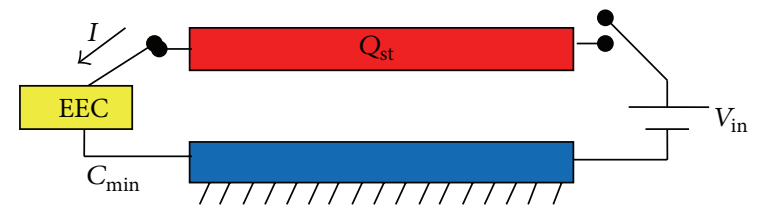

(d)

FIGURE 4: Operation of ES-VEH in constant charge mode.

2.3. Electromagnetic Vibration Energy Harvesters. Electromagnetic vibration energy harvesters (EM-VEHs) operate on the principle of Faraday's law of electromagnetic induction. An emf is induced in a closed loop (coil) when the magnetic flux density through the loop area is changed [30]. Generally, EM-VEH is composed of a permanent magnet, coil, and a suspension system. Due to vibration, there is relative motion between magnate and the coil in EM-VEH and an emf is induced in the coil [31]. Different architectures for EM-VEHs reported in literature are shown in Figure 7. The architectures used for the developed EM-VEHs include moving magnet and fixed coil EM-VEHs [32], moving coil and fixed magnet EM-VEHs [33], wound coil type EM-VEHs [34], planar coil type EM-VEHs [31], cantilever beam type EM-VEHs [35], fixed-fixed beam type EM-VEHs [36], and membrane type EM-VEHs [32]. 


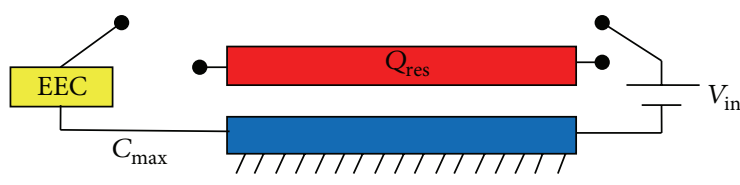

(a)

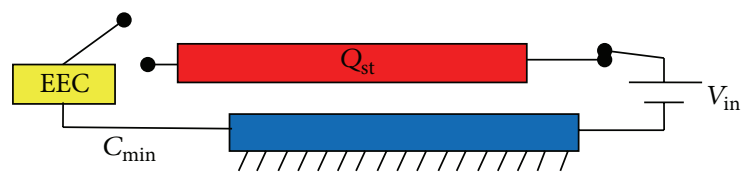

(c)

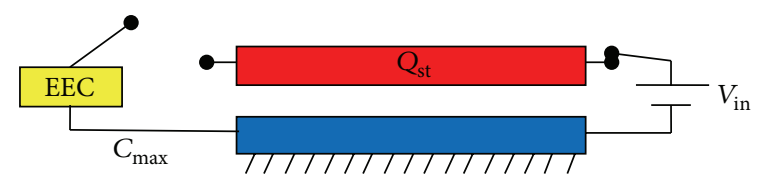

(b)

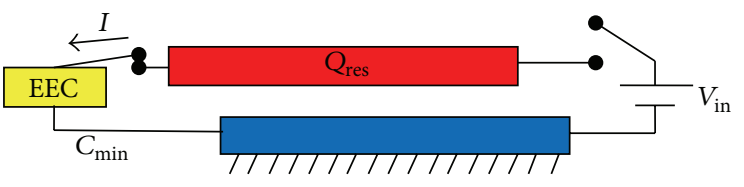

(d)

FIGURE 5: Operation of ES-VEH in constant voltage mode.

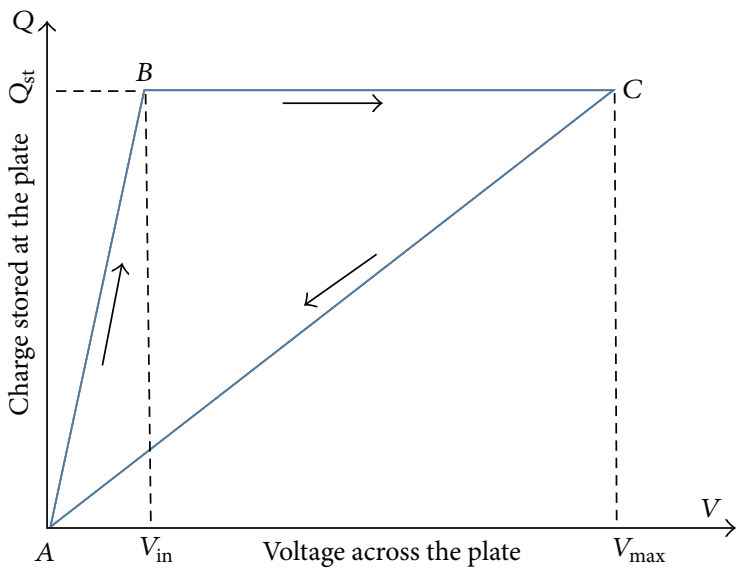

(a)

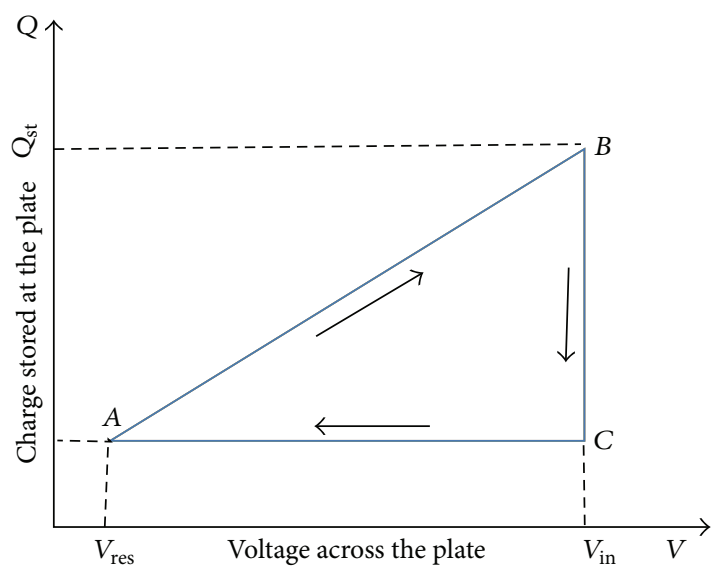

(b)

FIgURE 6: (a) Charge versus voltage at constant charge mode. (b) Charge versus voltage at constant voltage mode.

In EM-VEH, the coil is normally made from diamagnetic material that offers very weak force of repletion to permanent magnet and attribute to very low damping. The wound coil in EM-VEH is normally produced from copper wire [37]. However, various diamagnetic materials that are available for producing the microfabricated planar coils in EM-VEHs are shown in Table 4. Among these materials silver has the least electrical resistivity and can be suitable for making planar coil for EM-VEHs. However, due to the compatibility with other microfabrication materials and micromachining processes copper, Aluminum, and gold are mostly utilized for producing planar coils.

In EM-VEHs, high magnetic flux density, permanent magnets take an essential part in conversion of vibrational energy to electrical energy. The various types of permanent magnets that are generally used in the developed EM-VEHs are listed in Table 5. Due to high residual magnetic flux density, neodymium $(\mathrm{NdFeB})$ permanent magnets are normally used in almost all of the reported EM-VEHs. However, the high Curie temperature of cast Alnico (AlNico), Samarium Cobalt (SmCo), and Sintered Alnico (AlNiCo) make these permanent magnets more suitable for high temperature applications.
The comparison of the three basic types of VEHs is shown in Table 6. PE-VEHs and ES-VEHs are capable of generating high voltage levels than that of EM-VEHs [32]. The voltage generation in EM-VEHs is on the low side (in $\mathrm{mV}$ range); therefore, the voltage rectification is a little difficult and normally ultra-low voltage diodes are used in the rectifier to perform the low voltage rectification [38]. In contrast to EMVEHs, the internal impedance of PE-VEHs and ES-VEHs is very high due to which low output current levels are available from these harvesters [32]. Moreover, ES-VEHs require a battery source for the continuous charging of the plates of the harvesters and also an energy extraction circuit (switching circuit) [29] to collect the harvested energy from ES-VEHs.

\section{Bridge Vibration Energy Harvesting}

Bridge produces vibration due to the vehicular motion and wind [39]. These vibration levels are used as base excitation for different type of bridge vibration energy harvesters. A bridge vibration energy harvester converts bridge vibrations into electrical energy. Various types of bridge vibration energy harvester have been developed and reported. However, PE-VEHs and EM-VEHs are commonly used to extract the energy from the available bridge's excitations. 


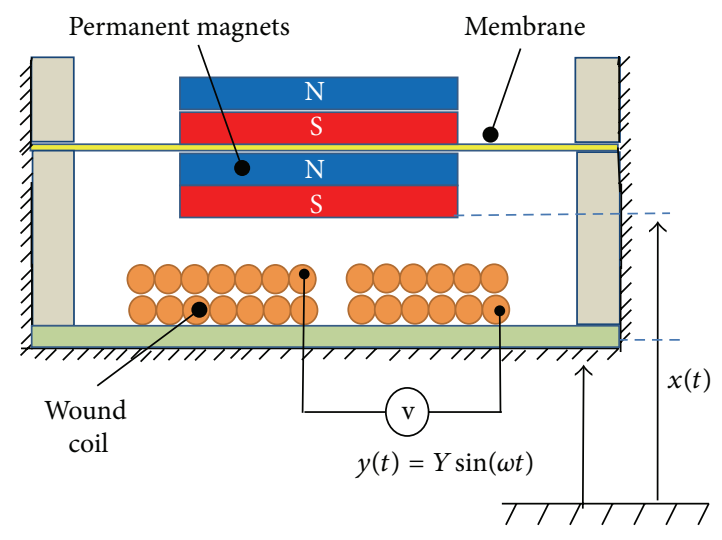

(a)

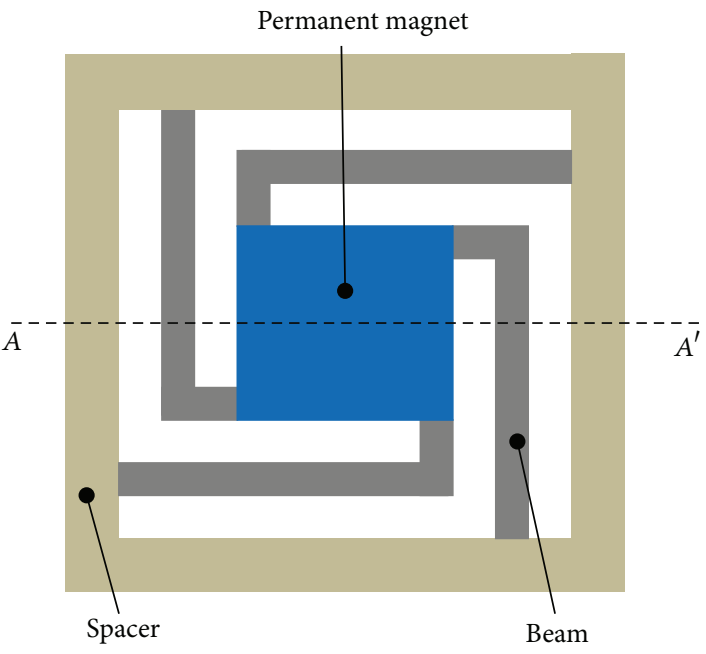

(c)

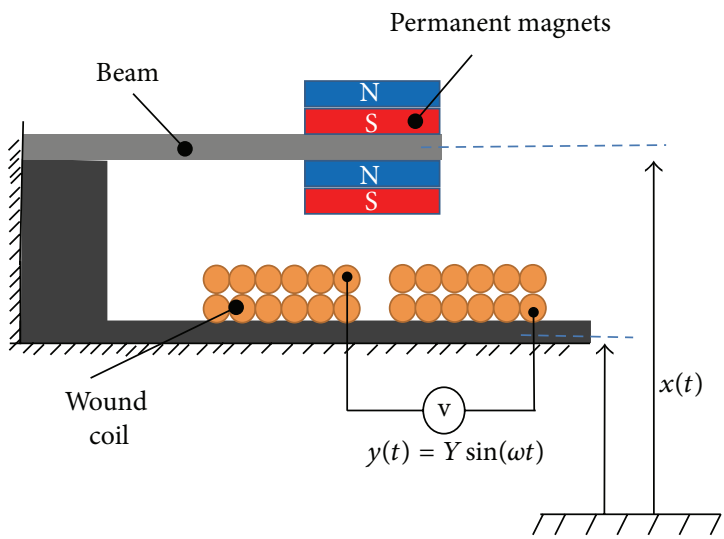

(b)

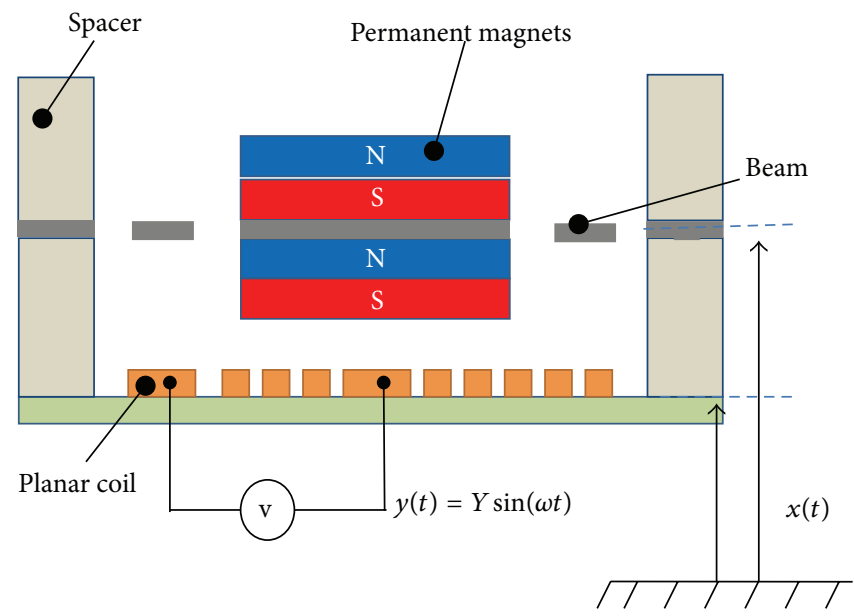

(d)

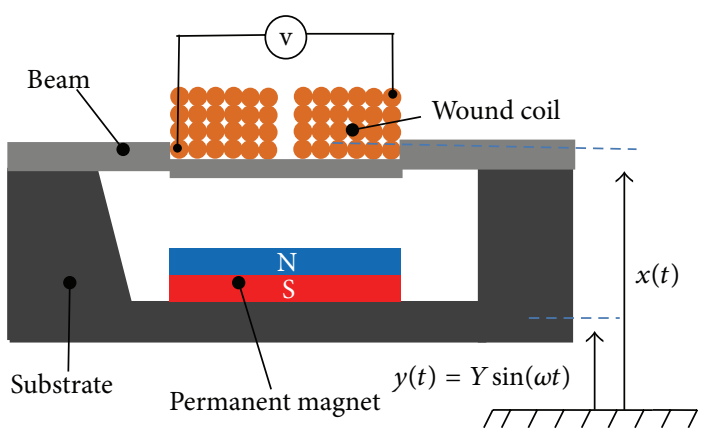

(e)

FIGURE 7: Schematic diagram of reported EM-VEHs: (a) membrane type EM-VEH, (b) cantilever beam type EM-VEH, (c) top view of beam type EM-VEH, (d) cross-sectional view of beam type EM-VEH, and (e) moving coil type EM-VEH.

TABle 4: Planar coil materials and their properties.

\begin{tabular}{lcccc}
\hline Coil materials & Relative permeability & $\begin{array}{c}\text { Density } \\
\left(\mathrm{g} / \mathrm{cm}^{3}\right)\end{array}$ & $\begin{array}{c}\text { Electrical resistivity at } 20^{\circ} \mathrm{C} \\
(\mathrm{n} \Omega \cdot \mathrm{m})\end{array}$ & $\begin{array}{c}\text { Thermal conductivity } \\
(\mathrm{W} / \mathrm{mK})\end{array}$ \\
\hline Copper & 0.99 & 8.96 & 16.78 & 401 \\
Silver & 0.99 & 10.4 & 15.87 & 429 \\
Aluminium & 1.00 & 2.7 & 28.2 & 237 \\
Gold & 1 & 19.3 & 24.4 & 318 \\
\hline
\end{tabular}


TABLE 5: Properties of permanent magnets used in EM-VEHs.

\begin{tabular}{|c|c|c|c|c|c|}
\hline Magnet materials & $\begin{array}{c}\text { Recoil } \\
\text { permeability }\end{array}$ & $\begin{array}{l}\text { Density } \\
\left(\mathrm{g} / \mathrm{cm}^{3}\right)\end{array}$ & $\begin{array}{c}\text { Curie } \\
\text { temperature }\left({ }^{\circ} \mathrm{C}\right)\end{array}$ & $\begin{array}{l}\text { Ultimate tensile strength } \\
\text { (kpsi) }\end{array}$ & $\begin{array}{l}\text { Residual flux density } \\
\text { (Tesla) }\end{array}$ \\
\hline Neodymium (NdFeB) & 1.05 & 7.4 & 310 & 12 & 1.4 \\
\hline Smarium Cobalt (SmCo) & 1.05 & 8.4 & 825 & 5 & 1.1 \\
\hline Sintered Alnico (AlNiCo) & 1.7 & 6.8 & 810 & 65 & 0.62 \\
\hline Cast Alnico (AlNiCo) & 1.7 & 7.3 & 860 & 5.4 & 1.2 \\
\hline
\end{tabular}

TABLE 6: Comparison of basic types of vibration-based energy harvesters.

\begin{tabular}{lccc}
\hline Parameters & PE-VEHs & ES-VEHs & EM-VEHs \\
\hline Output voltage & High & High & Low \\
Output current & Low & Low & High \\
Output impedance & High & High & Low \\
Resonant frequency & Low & High & Low \\
Voltage rectification & Easy & Easy & Hard \\
Switching circuit & No & Must & No \\
\hline
\end{tabular}

3.1. Electromagnetic Bridge Vibration Energy Harvesters. An aircore linear EM-VEH has been reported in [14] to harvest from the bridge vibrations. The developed EM-VEH is single phase harvester that is capable of generating high voltage, low current and has high coil resistance due to large number of turns. The energy harvester consisted of permanent magnets, a coil and spring. The spring used has a stiffness of $34 \mathrm{~N} / \mathrm{m}$, and in the coil vicinity the flux density of the magnets is recorded to be $200-274 \mathrm{mT}$. The wound coil is made up of 10,000 turns with resistance of $67 \mathrm{k} \Omega$ and inductance of $34 \mathrm{H}$. The air gap (aircore) is provided to decrease the mechanical damping during the vibration. The developed EM-VEH is mounted on the girder of a bridge and the bridge's vibration is used to excite the device. At the resonant frequency of $3.1 \mathrm{~Hz}$ and $10 \mathrm{~mm}$ base displacement, the EM-VEH generated a power of $12500 \mu \mathrm{W}$. However, at the amplitude of $3 \mathrm{~mm}$ base displacement the harvester is able to produce $10 \mathrm{~V}$ peak voltage and $1000 \mu \mathrm{W}$ power. The device architecture and fabrication were not mentioned.

For bridge monitoring purposes an EM-VEH [15] is produced by a rapid prototyping, $3 \mathrm{D}$ printing technology. The CAD model and the photograph of the fabricated EM-VEH are shown in Figure 8. In the harvester, the teeth, springs, and mounting clamps were 3D printed as one single part by using selective laser sintered Nylon plastic. The harvester's parts which are not possible to be produced by $3 \mathrm{D}$ printing were conventionally machined or purchased. The reported EM-VEH included permanent magnets assembly which is allowed to vibrate vertically with the help of an Aluminum shaft and two linear ball bearings. An Aluminum shaft is passed through the central holes in magnet's assembly and is supported by the bearings located in the end caps. Moreover, magnets located at each end are used as the springs to repel the vibrating magnet. The repulsive magnets are actually placed at the end caps which are screwed onto the casing of the harvester. A nonlinear spring stiffness produced due to the repulsive magnets is intended to broaden the bandwidth and also to provide a simple frequency tuning mechanism. The vibrating magnets assembly is produced by sandwiching iron alloy (that has high magnetic saturation and permeability) disks between the opposing NdFeB magnets. A threaded rod (nonmagnetic) with nuts at each end is utilized to keep the disks-magnets assembly. Due to the iron disks a high magnetic flux density is produced over a series of fixed wound coils that surrounded the vibrating magnets. The harvester is designed in such a way to be easily mounted onto the web-stiffener plate or cross-frame of the bridge structure. The developed EM-VEH when tested on a vibrating shaker produced an optimum power of $26 \mathrm{~mW}$ at acceleration amplitude of $0.08 \mathrm{~g}$ and frequency of $2.2 \mathrm{~Hz}$. The prototype energy harvester is only characterized inside the lab, under sinusoidal excitations, and is not tested for the real bridge vibration which due to passing traffic is pulsating and random in nature.

An EM-VEH [18] developed for extracting the energy from the vibration of urban infrastructure (e.g., bridges, rail tracks, and highways) is shown in Figure 9. The reported EM$\mathrm{VEH}$ is comprised of acrylic pipe, four NdFeB magnets, and a wound coil produced at the surface of the pipe. Two magnets are mounted at each end of the pipe; however, the remaining two are attached together and are allowed to suspend inside the pipe due to the repulsive force offered by the end magnets. When the developed EM-VEH is installed on the Seongdong bridge, at $8 \mathrm{mg}$ acceleration amplitude and $14 \mathrm{~Hz}$ dominant frequency (bridge vibration's frequency band $=9$ to $50 \mathrm{~Hz}$ ) produced a maximum voltage of $10 \mathrm{mV}$ and an average power of $2 \mu \mathrm{W}$. In the reported energy harvester, the conducting wire is wrapped around a small portion of the cylindrical portion, which actually resulted in small power generation. Moreover, for the device only length is mentioned, the diameter or volume of the harvester is not provided which might be helpful in computing the power density generated by the prototype.

An EM-VEH for harvesting energy from low frequency and nonperiodic vibration is developed in [40]. The developed harvester is reported as paramagnetic frequency increased generator (PFIG). The energy harvester (PFIG) consisted of a wound coil ( $2 \mathrm{~mm}$ width and $3.175 \mathrm{~mm}$ length), magnets $($ diameter $=3.175 \mathrm{~mm}$ and thickness $=4.75 \mathrm{~mm}$ ), copper suspension, tungsten mass, and Aluminum casing as shown in Figure 10.

The PIFG has been developed with a hybrid fabrication technique in which standard microfabrication lithographic 


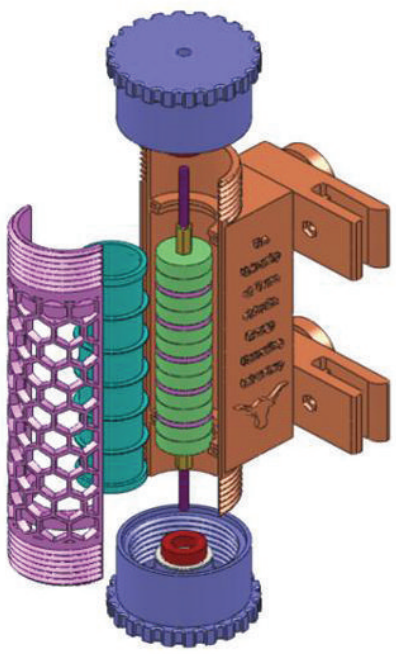

(a)

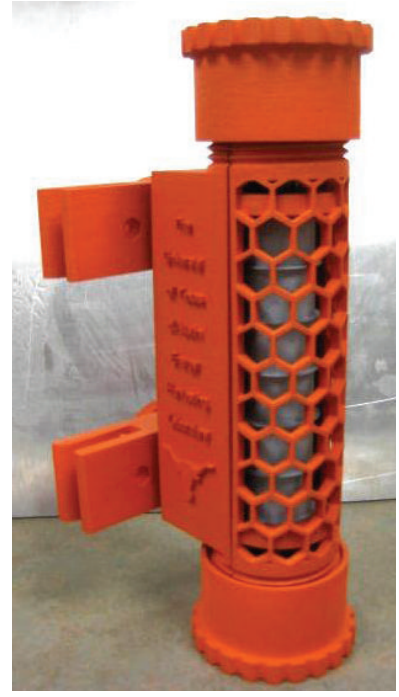

(c)

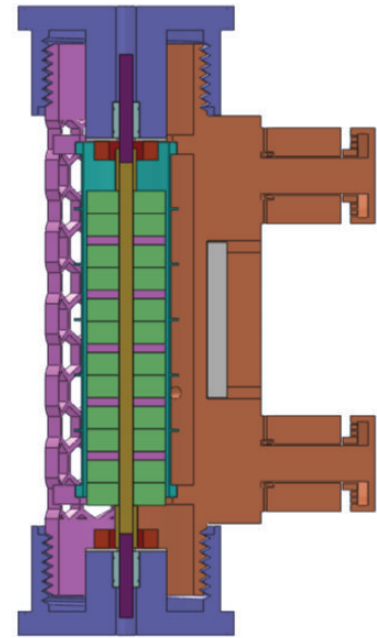

(b)

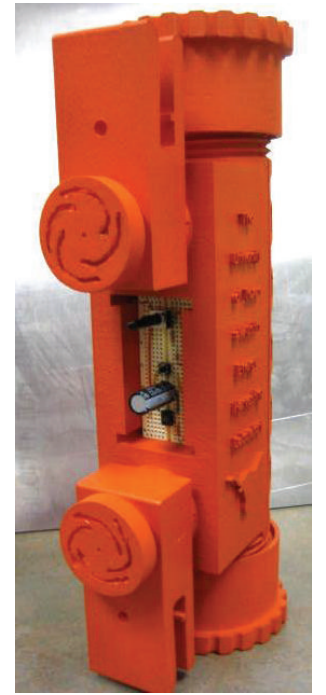

(d)

Figure 8: EM-VEH developed by [15]: (a) exploded view of EM-VEH prototype, (b) cross-section view of EM-VEH, (c) 3D printed EM-VEH, and (d) assembled EM-VEH with vibrating magnet structure.

processes are combined with conventional machining as shown in Figure 11. For inertial mass and each frequency increased generator (FIG), the planar springs are microfabricated (photolithography) by the selective etching of $127 \mu \mathrm{m}$ thick copper (alloy 110) sheet. The main magnet (NdFeB) and latching-actuation magnet are bonded to the spring to produce the FIG assembly. The wound coils are made over the bobbins (Aluminum) from the copper (44 AWG enameled) wire. With a single screw at the centre, the bobbin and the coil are fixed inside the FIG. The inertial mass (tungsten carbide) produced by electric discharge machining is bonded to each side of another planar spring. The FIG and the inertial mass subassemblies are then joined together using screws. When attached to the load resistance of $220 \Omega$ and excited at $1 \mathrm{~g}$ base acceleration and $10 \mathrm{~Hz}$ frequency, the reported PFIG produced a max power of $163 \mu \mathrm{W}$. The device experimentation has been performed in the lab using vibration shaker, and no real time characterization for the harvester has been investigated in the work.

As shown in Figure 12, an EM-VEH with multirepulsively stacked magnets and movable wound coils has been reported for low vibration environments [16]. The EM-VEH consisted of two wound coils. There are 980 turns in Coil-1; however, Coil-2 is made up of 1960 turns. The overall thickness of Coil1 and Coil- 2 is $2 \mathrm{~mm}$ and $4 \mathrm{~mm}$, respectively, and resistance of 145 and $290 \Omega$, respectively. Eight NdFeB magnets and seven steel cores, with each having thickness of $5 \mathrm{~mm}$, are attached on a steel shaft. The developed energy harvester is simulated for the vibration levels available at the third Nongro Bridge (South Korea) and the simulation results 

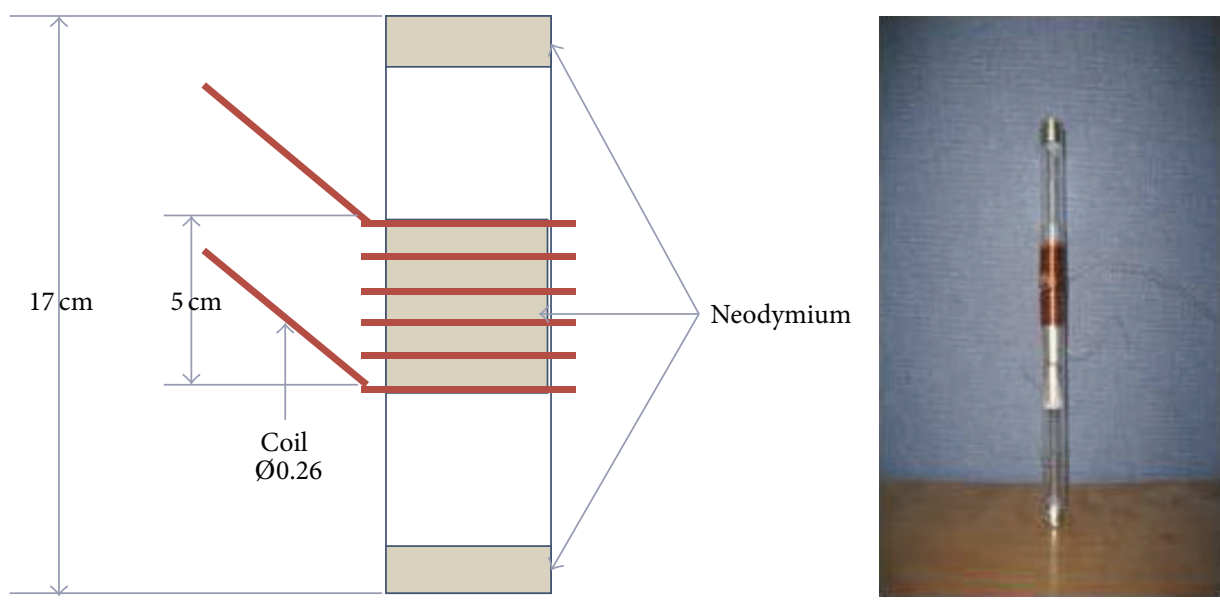

FIGURE 9: EM-VEH reported in [18] for bridge vibration energy harvesting.

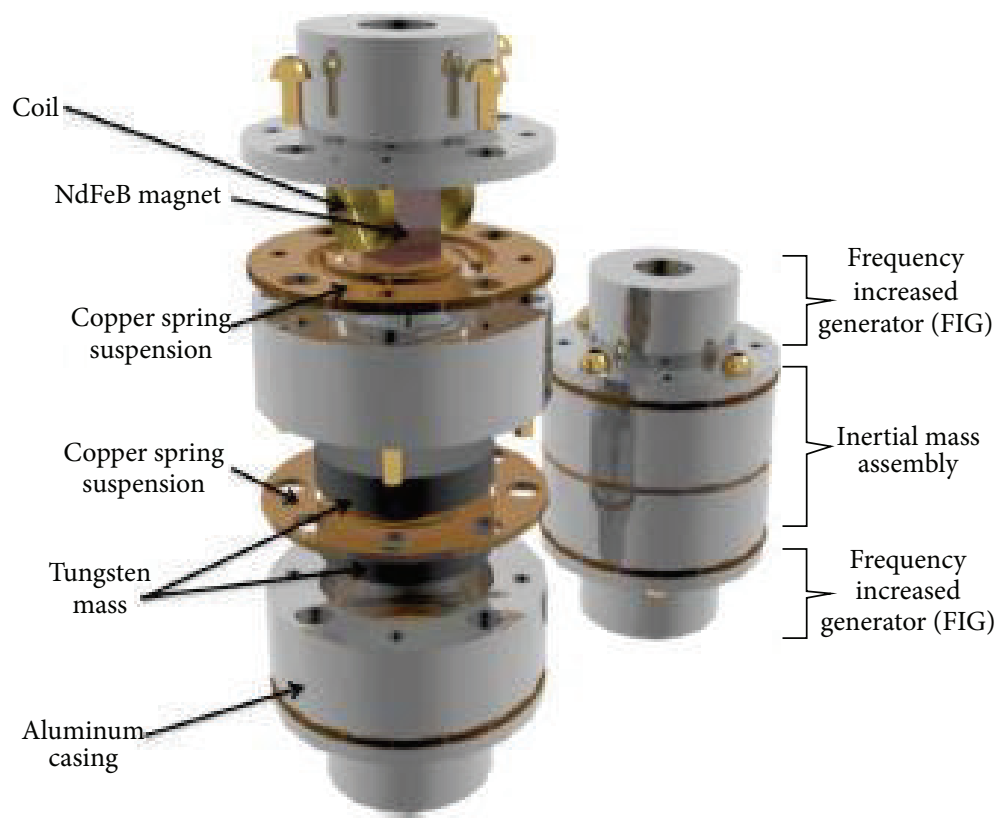

Figure 10: Exploded view of EM-VEH [40].

showed an average power generation of $0.12 \mathrm{~mW}$ from an input acceleration level of $0.025 \mathrm{~g}$ at $4.1 \mathrm{~Hz}$ frequency. Single coil of the device produced a voltage amplitude of $0.71 \mathrm{~V}$ and an rms voltage of $0.14 \mathrm{~V}$. The reported energy harvester is not characterized for the real bridge environment and, moreover, in the simulation performed in the lab the effect of wind and air surges produced due to passing traffic is not considered.

The EM-VEH reported in [37] consisted of Planar PCB coils, wound coils, membrane, magnets, and Teflon spacers. Assembled view of the reported EM-VEH is shown in Figure 13. The different parts of the EM-VEH are produced using PCB fabrication techniques and traditional machining processes. From a FR4, PCB board, a double sided planar coil of overall size of $1 \times 1 \mathrm{~cm}$ is developed with PCB fabrication technique. The planar coil has a wire width of $200 \mu \mathrm{m}$ and is composed of 12 turns. Wound coils are made from $0.18 \mathrm{~mm}$ copper wire. Copper wire is manually wound on the Teflon spacers to produce 7 turns wound coil for the harvester. The planar coil and wound coil have a resistance of 3.6 and $1.8 \Omega$, respectively. A flexible membrane is clamped in between two NdFeB magnets and this membrane-magnets suspension system is bonded in between the two Teflon spacers. FR4 substrate with dual planar coils is then attached to the spacer with epoxy. The prototype energy harvester has four planar and sixteen wound coils. The EM-VEH is characterized under sinusoidal vibration at different acceleration levels. At a resonant frequency of $27 \mathrm{~Hz}$ and acceleration amplitude of $3 \mathrm{~g}$, a single planar and wound coil of the EM-VEH produced a voltage of $15.5 \mathrm{mV}$ and $11.05 \mathrm{mV}$ and a load power of $1.8 \mu \mathrm{W}$ and $2.1 \mu \mathrm{W}$ at their matching impedance of $3.6 \mathrm{ohm}$ 


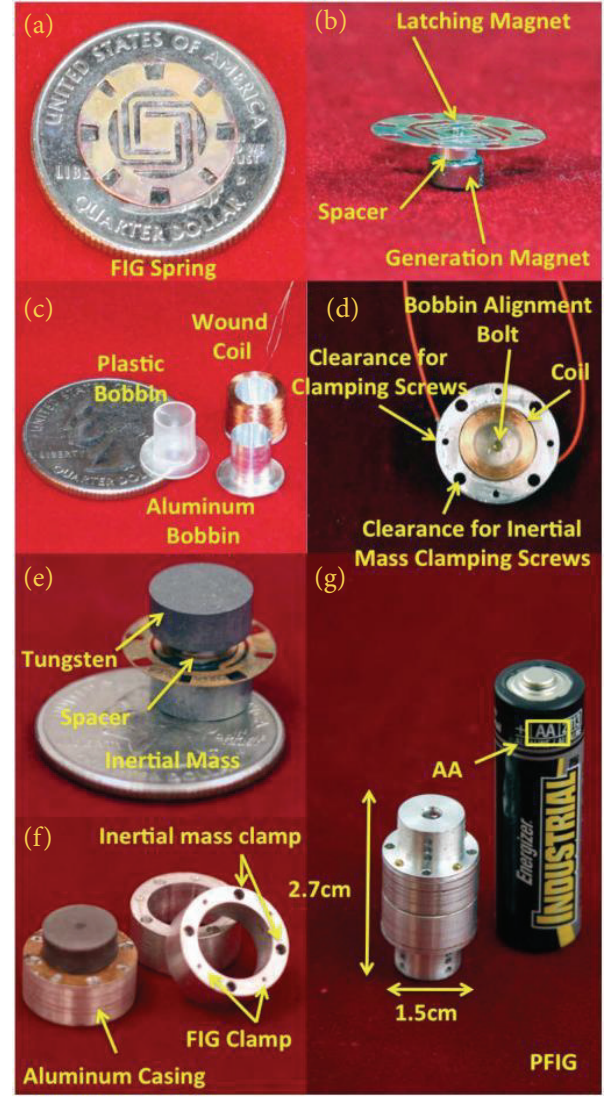

FIGURE 11: Fabrication of EM-VEH, reported by [40].

and $1.8 \mathrm{ohm}$, respectively. The resonant frequency $(27 \mathrm{~Hz})$ of the developed energy harvester is a little bit on higher side. Moreover, the harvester is only tested in the lab under sinusoidal excitation and the behaviour of the device is not investigated in the actual vibration of bridge. The membrane type energy harvesters normally exhibit nonlinear behaviour at high acceleration levels; however, this seeking of operation of the device is not discussed here.

Modeling and simulation for an EM-VEH are performed in [41]. The proposed devices are used to harvest energy from the wind induced vibrations of the suspension bridge. A suspension bridge of $766 \mathrm{~m}$ length is modeled in SAP2000 and with utilizing the wind speed data, the vibration response of the bridge is obtained. The wind induced vibration response of the bridge is then utilized to forecast the power generation with EM-VEH models. A simulated EM-VEH-1 consisted of a wound coil, suspended magnet, and a fixed magnet. In the central recess of the wound coil, the suspended magnet is allowed to vibrate on top of fixed magnet. In the harvester, magnets are oriented in such a way to repel each other during oscillations. The simulations performed on a linear EM-VEH1 model predicted a maximum power generation of $0.056 \mathrm{~mW}$ at the mid span of the bridge. Moreover, it is mentioned that in the middle portion $(305 \mathrm{~m})$ of the bridge the energy harvesting per harvester is larger than $0.001 \mathrm{~W}$. Modeling and simulation are also performed for a nonlinear EM-VEH2. The architecture of EM-VEH-2 is similar, except there is also a fixed permanent magnet on top of the suspended magnet. For an equivalent damping ratio of 0.02 , a peak power of $1.45 \mathrm{~W}$ is reported at the mid span of the bridge. In the reported energy harvesting work, only simulations are conducted for the bridge vibration (due to wind) and the energy harvester. The harvester fabrication is not reported; furthermore, during modeling and simulations the passing traffic, induced excitations are ignored.

For a bridge stay cable vibration control, a doublefunction EM-VEH is investigated in [42]. The reported electromagnetic damper is to provide vibration damping in the bridge stay cable as well as extract the energy from the bridge vibrations. The double-function electromagnetic damper is comprised of EM-damper and an energy harvesting circuit. A discontinuous conduction mode (DCM) buckboost converter is used to obtain the optimum operational points of the reported EM-damper. For the performance of the EM-damper, numerical simulations are performed on a full scale wind excited stay cable. It is reported that, for the specific wind speed that range from $9 \mathrm{~m} / \mathrm{s}$ to $15 \mathrm{~m} / \mathrm{s}$, the EM-damper successfully performed the dual functions and with the harvester, an average energy generation efficiency of $42.3 \%$ is obtained. Moreover, at the optimum wind velocity range $(9 \mathrm{~m} / \mathrm{s}$ to $15 \mathrm{~m} / \mathrm{s})$, the simulation results also predicted a maximum power production ranging from $82.5 \mathrm{~mW}$ to $2.4 \mathrm{~W}$. In this research only the simulation of energy harvesting from a bridge stay cable due to the excitations by the wind speed is performed. No harvester's fabrication and experimentation have been conducted; moreover, the traffic induced vibration is not considered in the simulations which can affect the overall accuracy of the simulation results for the energy harvesting system.

\subsection{Piezoelectric Vibration Energy Harvesters. A PE-VEH} [15] developed for bridge monitoring system is shown in Figure 14. The harvester consisted of two Aluminum cantilever beams and a large mass (steel) at the beam's tip. Two small piezoelectric bimorph type (MIDE Volture) vibration energy harvesters are also placed at the free end of the main beam. Due to the excitation, as the main beam vibrates, the beam's tip hits a stopper plate oriented just beneath the tip. The impulsive striking caused the small piezoelectric bimorph beams to resonate at relatively higher resonant frequencies. The resonant frequency of the main beam is $2.07 \mathrm{~Hz}$. When the PE-VEH is subjected to a vibration at $2 \mathrm{~Hz}$ frequency, $0.1 \mathrm{~g}$ acceleration amplitude, and $6 \mathrm{~cm}$ displacement, an optimum power of $64 \mu \mathrm{W}$ is generated by a single bimorph beam at the optimum load of $70 \mathrm{k} \Omega$. The testing of the developed energy harvester is not reported for the real bridge vibration; moreover, the initial beam bending (due to proof mass) might cause nonlinear device behaviour even at lower acceleration levels.

For harvesting vibrations in civil structures, the developed tunable PE-VEH [26] is shown in Figure 15. The reported $\mathrm{PE}-\mathrm{VEH}$ is a cantilever type energy harvester and consisted of a commercially available bimorph PZT sensor (type: SMBA4510T05M, STEMIC) and a tip proof mass (3.75 grams). Two metallic coil type springs are used to 


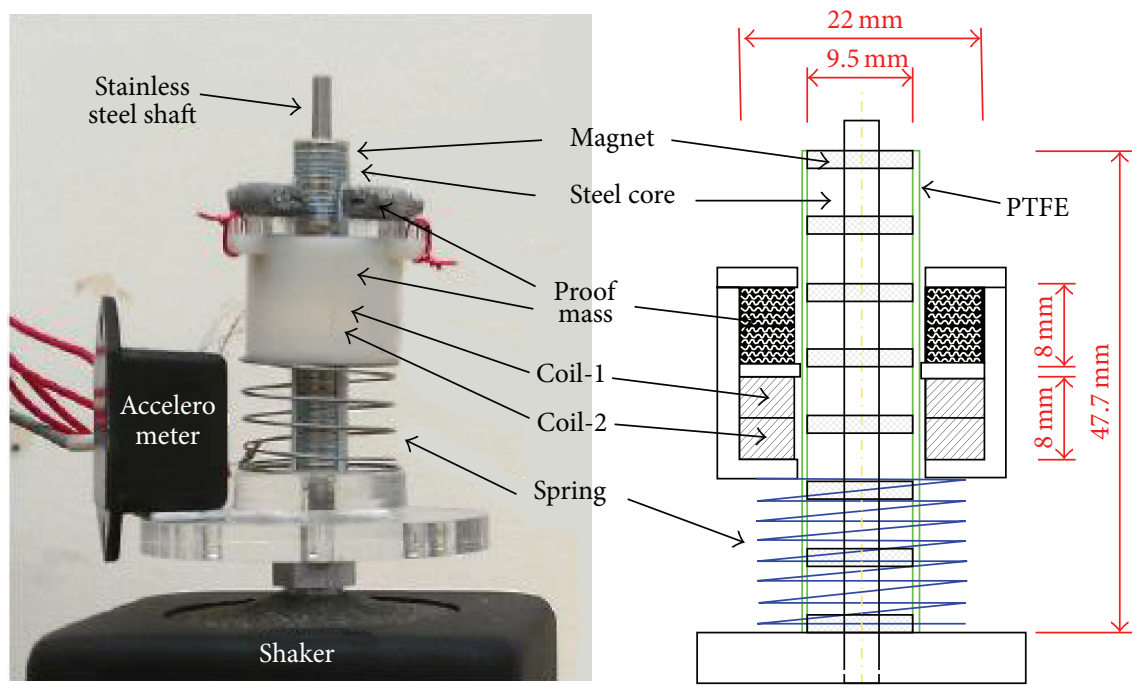

FIgURe 12: Device and experimental setup [16].

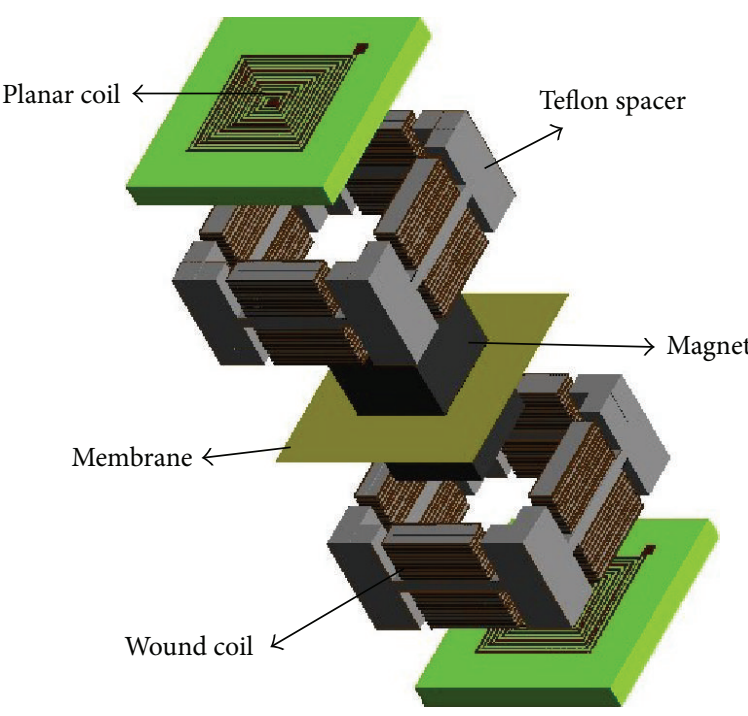

(a)

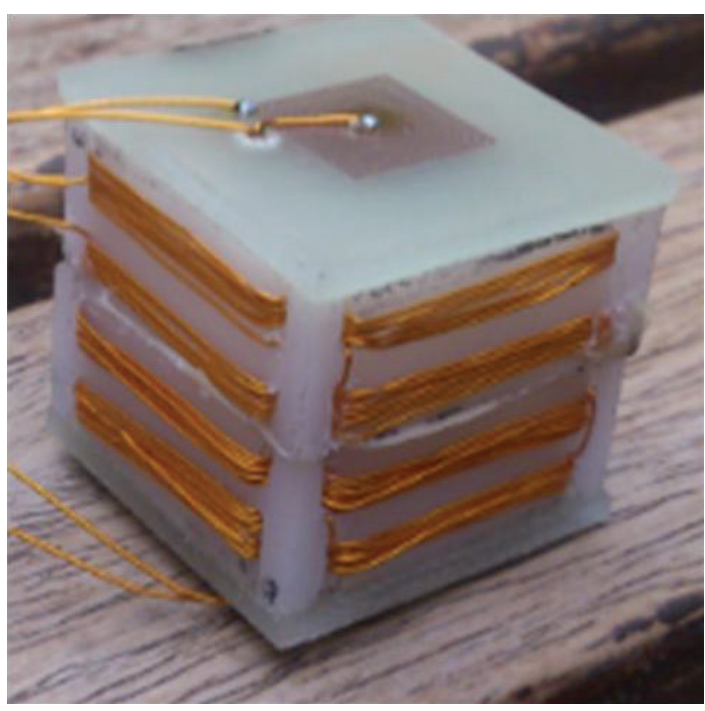

(b)

FIGURE 13: EM-VEH developed in [37]: (a) exploded view and (b) assembled prototype.

connect the beam's tip to the clamped beam's end. The objective of utilizing the coil spring is to provide the preload (prestress) to the bimorph beam. With the screws, the lengths of the springs are adjusted in order to alter the preload on the beam. When connected to a $10 \mathrm{M} \Omega$ load resistance and subjected to $1 \mathrm{~g}$ acceleration, the $\mathrm{PE}-\mathrm{VEH}$ produced a voltage of $27 \mathrm{~V}$ and $28 \mathrm{~V}$ under compressive preloads of $2 \mathrm{~N}$ and $4 \mathrm{~N}$, respectively. The corresponding resonant frequencies reported at these preloads $(2 \mathrm{~N}$ and $4 \mathrm{~N})$ are $44.5 \mathrm{~Hz}$ and $40 \mathrm{~Hz}$. Real experimentation on bridge has not been performed, and only lab characterization is discussed. Moreover, in the harvester, any slight difference in the spring forces for the beam preload will greatly affect the device performance.
The design, modeling, and characterization of the PE$\mathrm{VEH}$ have been investigated in [43]. The developed energy harvester shown in Figure 16 is a cantilever type energy harvester. To extract the energy from the frequency band $(15 \mathrm{~Hz})$ of bridge vibrations, the resonant frequency in the developed energy harvester is kept $14.5 \mathrm{~Hz}$. Two bimorph piezoelectric (MideQP20W) patches were bonded on the top and bottom surface of a steel plate which has a dimension of $40 \times 220 \times 0.8 \mathrm{~mm}$. The piezoelectric patches were glued near the clamped end of the cantilever beam. For the resonant frequency tuning of the harvester a $12 \mathrm{~g}$ mass is placed on the steel beam as a proof mass. The developed PE-VEH is tested on the bridge and, at a frequency of lower than $15 \mathrm{~Hz}$, it successfully produced a maximum power of $30 \mu \mathrm{W}$ and 


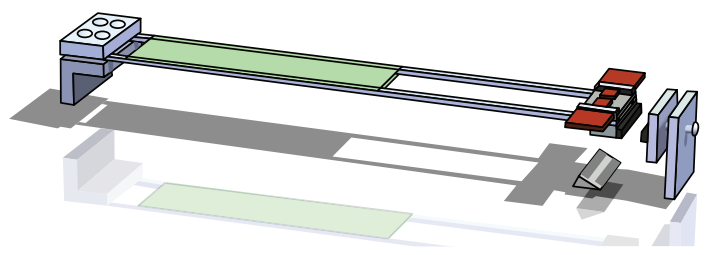

(a)

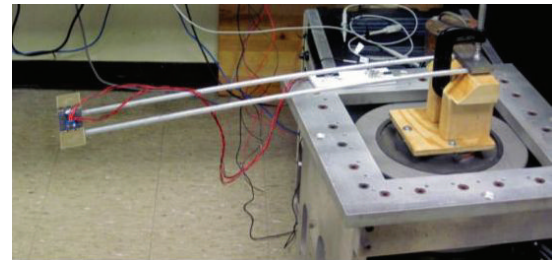

(b)

FIGURE 14: PE-VEH developed by [15]: (a) CAD model of PE-VEH prototype and (b) developed PE-VEH on the vibration shaker.

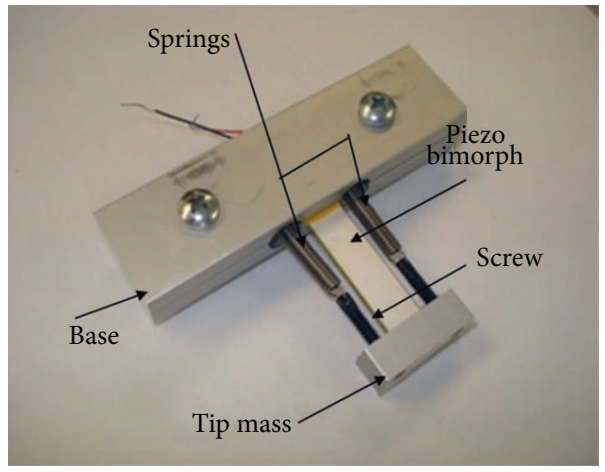

(a)

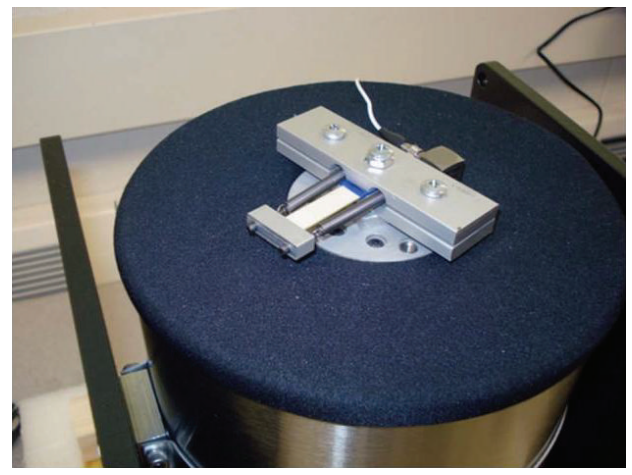

(b)

FIGURE 15: PE-VEH produced for vibration in civil structures [26].

a voltage that ranges from 1.8 to $3.6 \mathrm{~V}$. Since the reported harvester is mounted at the fixture of water pipe passing under the bridge, therefore, it might be possible that high wind speed hampers the operation of the harvester.

The bridge vibration interaction with the piezoelectric energy harvester is reported in [44]. Analytical modeling for bridge vibration and $\mathrm{PE}-\mathrm{VEH}$ is performed in time domain and frequency domain. The bridge dynamics is modeled as a simply supported beam with a constant moving load; however, the PE-VEH is modeled as one degree of freedom system. The developed models are simulated for different parameters, such as bridge length $(25,50,75$, and $100 \mathrm{~m})$, vehicle velocity $(20,40,60,80$, and $100 \mathrm{mi} / \mathrm{h})$, bridge damping ratio $(0.01,0.03$, and 0.05$)$, and the location of the piezoelectric (PVDF) harvester on the bridge $(1 / 4,1 / 2$, and $3 / 4$ of bridge's length). The simulation results showed a maximum power generation either at $20 \mathrm{mi} / \mathrm{h}$ or at $40 \mathrm{mi} / \mathrm{h}$. Bridge lengths of $75 \mathrm{~m}$ and $100 \mathrm{~m}$ produced sufficient power to operate microsensors. However, the prospective harvester's locations, $1 / 4$ th and $3 / 4$ th, of the bridge lengths are reported to have enough potential for the considered bandwidth of the vehicle velocities. Moreover, for a vehicle $(1000 \mathrm{~N})$ velocity of $20 \mathrm{mi} / \mathrm{h}$ over a $100 \mathrm{~m}$ long bridge, a maximum simulated power of $0.6 \mu \mathrm{W}$ is reported at 3/4th bridge's length. Only modeling and simulation have been performed, and the PE$\mathrm{VEH}$ fabrication and its implementation are not mentioned.

In [45], a multi-impact cantilever type PE-VEH is developed for low frequency (less than $10 \mathrm{~Hz}$ ) vibrations of structures, such as bridges. The reported energy harvester (shown in Figure 17) consisted of a frame, two vertically oriented piezoelectric cantilever beams, and a mass-spring system (hung mass) aligned in between the two vertical beams. A piezoelectric patch (PI P-876) is bonded near the clamped end of each vertical Aluminum cantilever beam; however, there are a number of bulges on the remaining portion of the beam. The mass containing the rollers on the sides is suspended by the coil spring. During vibrations, when the rollers move along the mass, the bulges at the tips of the cantilevers are repeatedly struck by the rollers. Due to these impacts, high frequency vibrations $(120 \mathrm{~Hz})$ are triggered in the horizontal 


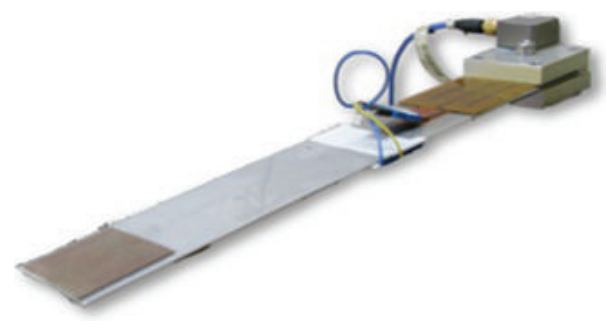

(a)

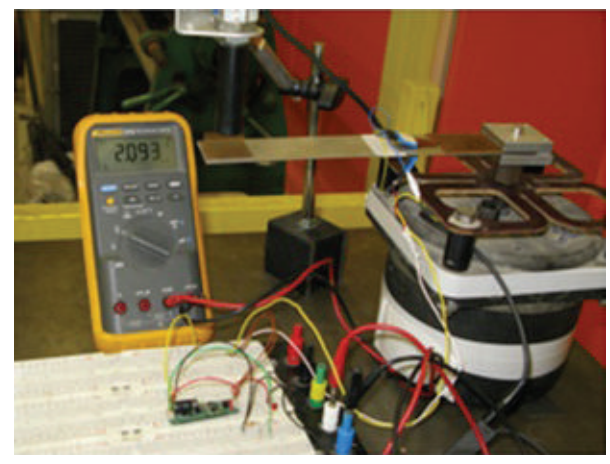

(b)

FIGURE 16: (a) Piezoelectric energy harvester (b) experimental setup [43].

direction on the cantilever beams. In this manner, the low frequency external vibration is converted into the vertical oscillation of the hung mass and then into the high frequency excitation (horizontal) of cantilevers. When the reported $\mathrm{PE}-\mathrm{VEH}$ is subjected to a sinusoidal excitation at $0.29 \mathrm{~g}$ acceleration amplitude and $2.71 \mathrm{~Hz}$ (resonant frequency of hung mass), an average power of $7.7 \mathrm{~mW}$ is produced under optimum load condition of $9.7 \mathrm{k} \Omega$. Moreover, at resonance and under the same load matching condition, a maximum average power of almost $9.4 \mathrm{~mW}$ is reported at a base acceleration of $4.4 \mathrm{~g}$ for the energy harvester. However, when the $\mathrm{PE}-\mathrm{VEH}$ is characterized for the simulated bridge vibrations, the harvester delivered a maximum average power of $2.8 \mathrm{~mW}$ to the optimum load resistance of $9.7 \mathrm{k} \Omega$. It is reported that, under the simulated bridge excitations, the working of the $\mathrm{PE}-\mathrm{VEH}$ is not as smooth as in case of sinusoidal vibrations. When compared with the fabricated traditional cantilever type PE-VEH (same resonant frequency of $2.71 \mathrm{~Hz}$ ), the performance of the multi-impact type PE-VEH is found far better. For the reported device the performance is only analyzed in the lab using vibration shaker. Moreover, due to sudden impacts between beams and hung mass, the beams wear and fatigue can be an issue.

For the bridge vibration analysis, modeling of a bridge's model with a moving point load and an analytical modeling of a vibration-based piezoelectric energy harvester have been discussed in [46]. A PE-VEH with and without inductor has been modeled as a single degree of freedom system and simulated using the devised bridge's model. A moving point load at various vehicle speeds $(10,15,20$, and $25 \mathrm{~m} / \mathrm{s})$ is assumed at different locations $(1 / 4,1 / 3$, and $1 / 2$ of the

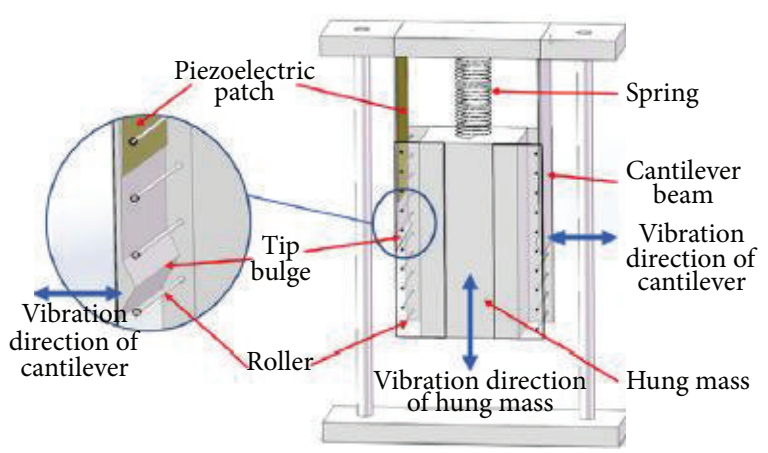

(a)

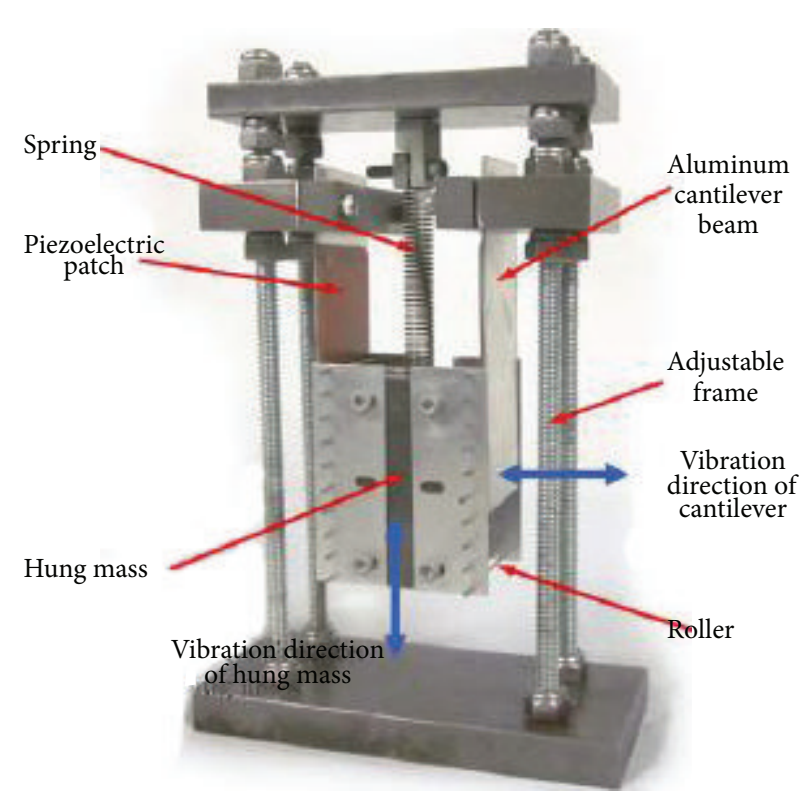

(b)

FIgURE 17: Multi-impact PE-VEH developed by [45]: (a) CAD model and (b) assembled energy harvester.

bridge's length) of the bridge and energy is estimated at different bridge's length. Both time and frequency responses are obtained at various bridge's locations and it is reported that the optimum power is harvested at the location where both the PE-VEH resonant frequencies matched with the bridge's natural frequency. A simulated, maximum energy generation of about $18 \mu \mathrm{J}$ is reported at $1 / 3$ of the bridge's length for a vehicle speed of $25 \mathrm{~m} / \mathrm{s}$. In this work only the bridge model and energy harvester have been analyzed and simulated, and no device fabrication and real time experimentation are performed.

A piezoelectric energy harvester is developed [47] for extracting the energy from vibration available at the bridge bearing. The prototype PE-VEH consisted of a 0.5 in thick steel plate $(6$ in $\times 26$ in) containing 6 PZT (Type 5A) piezoelectric wafers. The thickness of each PZT wafer is $2 \mathrm{~mm}$ and is bonded to the steel plate using conductive epoxy (Chemtronics CircuitWorks, CW2400). Moreover, a rubber 


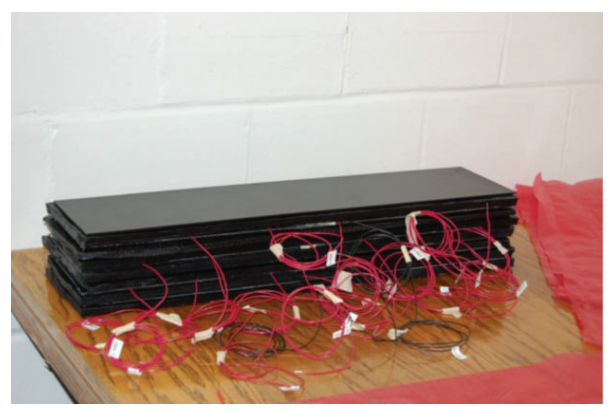

FIGURE 18: Fully-assembled bearing prototype [47].
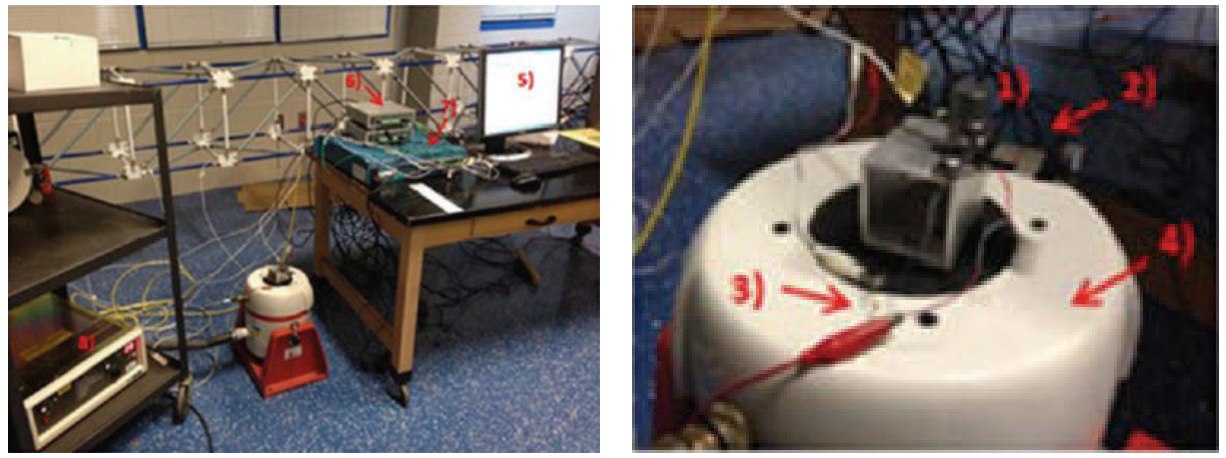

(1) Accelerometer

(2) Piezoelectric generator

(3) Load resistance

(4) Shaker
(5) Computer

(6) Function generator, data acquisition system

(7) Signal conditioner

(8) Power amplifier

FIGURE 19: Experiment setup for model validation [48].

(60-durometer neoprene) layer is inserted between the steel plates. The assembled bearing PE-VEH contained $5 \mathrm{PZT}$ bonded steel plates and rubber (60-durometer neoprene) layers $(3 / 8$ in $\times 6$ in $\times 26$ in $)$ which are inserted in between the overlap steel plates. A load resistance of $480 \Omega$ is attached to each PZT wafer and the prototype PE-VEH is subjected to a cyclic force (square wave) at different frequencies and force amplitudes. At optimal load condition and when subjected to a force amplitude of $4 \mathrm{kip}$ and a frequency of $1.5 \mathrm{~Hz}$, the total energy (Watt-seconds) dissipated in the load resistance in 2 seconds is reported to be $1.67 \times 10^{-4} \mathrm{~W} \cdot \mathrm{s}$, which corresponds to the harvester's instantaneous total power generation of 8.35 $\times 10^{-5} \mathrm{~W}$. Moreover, at a frequency of $2 \mathrm{~Hz}$ a peak voltage of $650 \mathrm{mV}$ is reported. The developed prototype is shown in Figure 18. The reported device is only characterized in lab, and the implementation of the developed energy harvester in the actual bridge bearing can be an issue regarding the compromise on the structural strength and stability.

For the structural health monitoring of bridges, modeling and fabrication of a PE-VEH are reported in [48], and the experimental setup is shown in Figure 19. The developed $\mathrm{PE}-\mathrm{VEH}$ consisted of a bimorph piezoelectric (Piezo System Inc., T226-A4-503X) cantilever beam. Two prototypes are reported, prototype-1, which is only the bimorph cantilever beam (without tip mass) and has a resonant frequency of $117.1 \mathrm{~Hz}$. However, in prototype-2, tip mass is added at the free end of the beam and its resonant frequency is $65.2 \mathrm{~Hz}$. The prototypes are subjected to sinusoidal excitation at $0.21 \mathrm{~g}$ acceleration level and respective device's resonant frequencies. At the optimum loads of $11.8 \mathrm{k} \Omega$ and $14.9 \mathrm{k} \Omega$, maximum power of 197 and $657 \mu \mathrm{W}$ is reported for prototype- 1 and prototype- 2 , respectively. The simulation of the devised model is reported to be in good agreement with the measurement. Moreover, for the broadband applications, an array type PE-VEH is also fabricated in this work. The broadband $\mathrm{PE}-\mathrm{VEH}$ composed of an array of six piezoelectric cantilever beams with different resonant frequencies (63.25, $76.63,71.5,66.25,63.13,58.88$, and $55.38 \mathrm{~Hz})$. Under optimum load condition $(7.3,6.6,6.8,7.1,7.3,7.5$, and $7.8 \mathrm{k} \Omega$ ), when subjected to a base acceleration of $0.2 \mathrm{~g}$, a power of 0.31 , $0.24,0.26,0.28,0.31$, and $0.33 \mathrm{~mW}$ is produced by each beam in the array. For the developed array type PE-VEH an average power of $0.22 \mathrm{~mW}$ is reported in the frequency range from 57 to $78 \mathrm{~Hz}$. In this publication the energy harvester is characterized under the vibration of a bridge model, and no experimentation on the real bridge is reported. Moreover, the developed prototypes exhibit relatively higher resonant frequencies ( 57 to $78 \mathrm{~Hz}$ ) and can be applicable only in those structures where this narrow frequency band bridge vibrations are available.

To power a structural health monitoring system from bridge vibrations, a computational model is developed for 
a PE-VEH [49]. The simulated PE-VEH is composed of a PVDF layer attached to the whole top surface of the bridge and the vibration produced due to a single vehicle passing over a simply supported bridge is considered for power generation. The vehicle is modeled as a moving point load crossing the bridge at a constant velocity. However, the bridge model is a $25 \mathrm{~m}$ long concrete (density of 2,446 and Young's modulus of $36 \mathrm{GPa}$ ) beam, with a rectangular cross-section (width of $8.5 \mathrm{~m}$ ) and a span to depth ratio of 20. The PVDF material with the density, Young's modulus, and dielectric constant of $1760 \mathrm{~kg} / \mathrm{m}^{3}, 3 \mathrm{Gpa}$, and $7.434 \times$ $10^{-11} \mathrm{~F} / \mathrm{m}$, respectively, is utilized for simulation. For analysis, a finite element software ABAQUS is used and the structure is analyzed using 2-dimensional, 8-nodded quadratic elements. For a $25 \mathrm{~m}$ and $30 \mathrm{~m}$ concrete (base beam) and PVDF bridges, the simulations reported a power production of $4.2 \mathrm{~kW}$ and $5.1 \mathrm{~kW}$, respectively. Moreover, the concrete (beam) bridge power generation results are also compared with steel (base beam) and PVDF bridges, and a much less power generation (only $0.058 \mathrm{~kW}$ and $0.096 \mathrm{~kW}$, resp.) is reported for the steel bridges. In this work the size of the simulated energy harvesting mechanism is gigantic. In reality, how the piezoelectric material will be attached to the road surface is not mentioned.

\section{Comparison of Bridge Vibration Energy Harvesters}

Developed bridge vibration energy harvesters are summarized in Table 7 . The comparative analysis of the reported bridge vibration energy harvesters can be performed on several criterions, such as harvester's size, transduction mechanism, resonant frequency, operation frequency, frequency bandwidth, internal impedance, optimum load, acceleration levels to which these are subjected, voltage generation, power production, and power density.

Based on the transduction mechanism, the bridge vibration energy harvesters are classified into EM-VEHs [15, 16, 37, 40, 41] and PE-VEHs [18, 44, 45, 47, 48]. In most of the developed PE-VEHs the commercially available piezoelectric material is utilized to fabricate the energy harvester. However, in EM-VEHs, mostly wound coils and permanent magnets are used to produce the devices. PE-VEHs produced high voltage levels; however, due to high internal impedance low power levels are generated. Although, relatively, low voltage levels are produced by EM-VEHs, because of low internal impedance in EM-VEHs, relatively high output current and power levels are obtained.

By virtue of the harvester's resonant frequency, most of the developed bridge vibration energy harvesters reside in the range of low resonant frequency $(<100 \mathrm{~Hz})$ devices. Only the harvesters reported in $[45,48]$ have resonant frequencies greater than $100 \mathrm{~Hz}$. Relatively the EM-VEHs have lower resonant frequencies than that of PE-VEHs. This fact is attributed to the larger proof mass (permanent magnet) in EM-VEHs than that of the PE-VEHs.

The classification of bridge vibration energy harvesters can also be performed with respect to the power production by these devices. Very low power levels $(0.6-57 \mu \mathrm{W})$ are
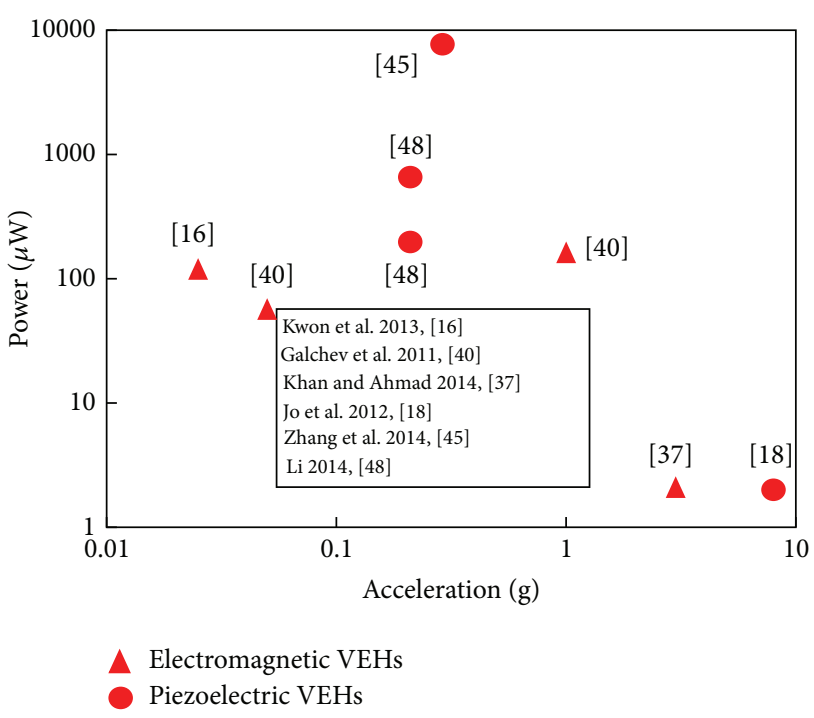

FIGURE 20: Power developed by the bridge energy harvesters as a function of acceleration.

generated by the harvesters reported in [18, 37, 40, 41, 44]. The energy harvesters reported by $[16,47,48]$ have generated relatively medium power levels, which is in the range of 120 to $657 \mu \mathrm{W}$. However, comparatively high power levels (7700 to $1450000 \mu \mathrm{W})$ are produced with energy harvesters developed in $[15,41,45]$.

Figure 20 shows the power generated by the developed bridge vibration energy harvester as function of base acceleration. The bridge vibration energy harvesters are subjected to an overall base acceleration that range from 0.025 to $8 \mathrm{~g}$. The EM-VEHs are relatively characterized under lower acceleration levels ( 0.025 to $3 \mathrm{~g}$ ), in comparison to PE-VEHs, which are subjected to 0.21 to $8 \mathrm{~g}$, acceleration levels. Based on the acceleration levels of the applied vibration, the reported bridge vibration energy harvester can be classified into low, medium, and high acceleration energy harvesters. Low acceleration level $(0.025$ to $0.29 \mathrm{~g})$ harvesters are reported by $[16,40,45,48]$. The developed harvesters $[15,40]$ are characterized under medium acceleration levels ( 0.3 to $1 \mathrm{~g}$ ). However, the harvesters operated under high acceleration levels $(3$ to $8 \mathrm{~g}$ ) are reported in $[18,37]$. The EM-VEH developed in [16] is operated under the lowest acceleration level of $0.025 \mathrm{~g}$; however, among the energy harvesters, a PEVEH [18] is subjected to the high acceleration level of $8 \mathrm{~g}$. Comparatively, the harvesters [45] and [48] produce high power levels at medium acceleration levels of 0.29 and $0.21 \mathrm{~g}$, respectively.

The power developed by the devised bridge vibration energy harvesters with respect to the harvester's size is shown in Figure 21. Most of the reported bridge vibration energy harvesters are mesoscale devices. Among the developed bridge vibration energy harvesters, the EM-VEH [40] has the smallest size $\left(4.8 \mathrm{~cm}^{3}\right)$ and produced a power of $163 \mu \mathrm{W}$. However, PE-VEH developed by [47] is of the biggest size $\left(12208.91 \mathrm{~cm}^{3}\right)$ and it reported to generated $167 \mu \mathrm{W}$. In comparison, the EM-VEH-2 [41], with a volume of $152 \mathrm{~cm}^{3}$, 


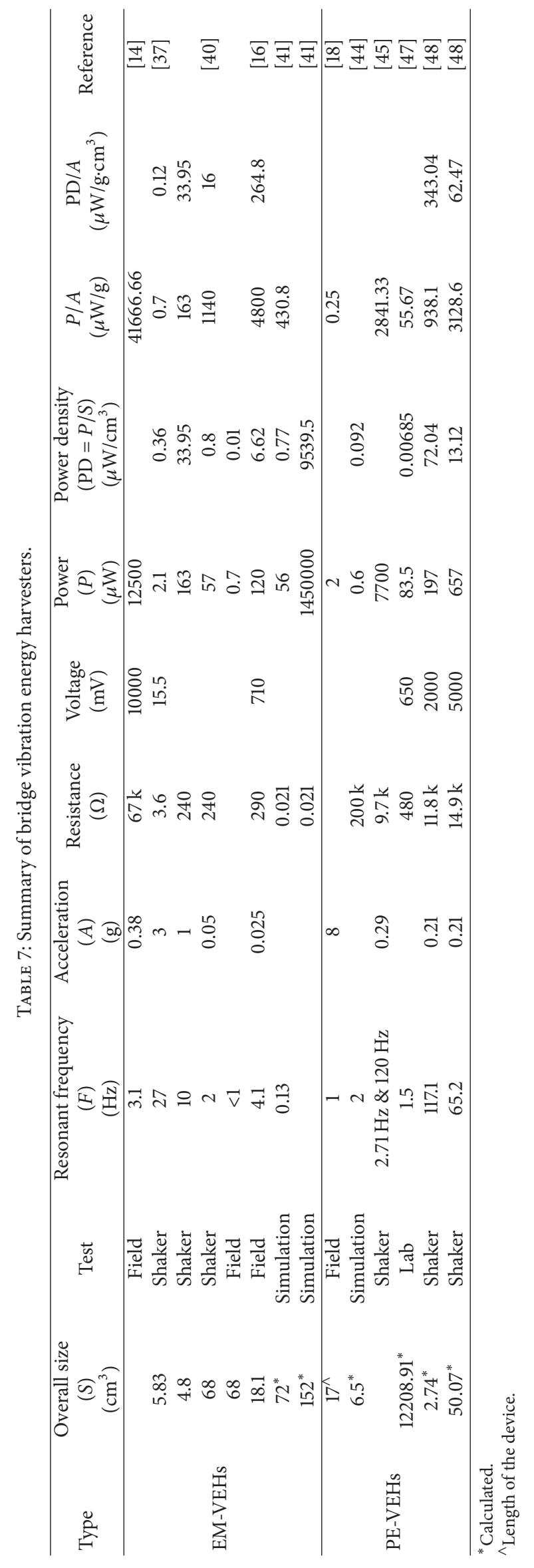




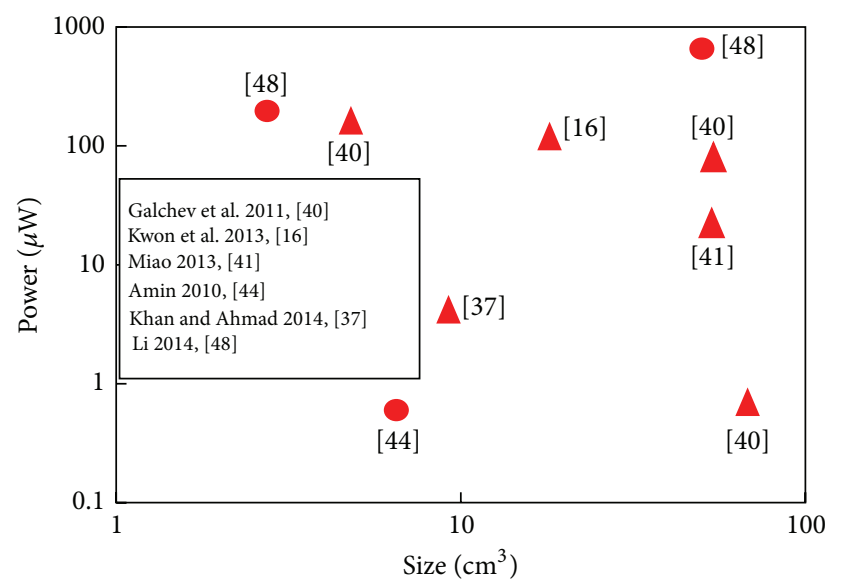

Electromagnetic VEHs

Piezoelectric VEHs

Figure 21: Power developed by the bridge vibration energy harvesters as function of harvester's size.

is mentioned to produce a simulated power of $1450000 \mu \mathrm{W}$, which is the largest among all the bridge vibration energy harvesters. However, the actual fabrication of the EM-VEH2 [41] is not reported. Moreover, the least power $(0.6 \mu \mathrm{W}$, simulated) is generated by a PE-VEH [44], which has a size of $6.5 \mathrm{~cm}^{3}$. By comparing the overall size, the EM-VEHs are relatively smaller in size, having the range from 4.8 to $152 \mathrm{~cm}^{3}$; however, the PE-VEHs are comparatively bigger in size (from 17 to $12208.91 \mathrm{~cm}^{3}$ ).

For the reported bridge vibration energy harvesters, the power density plotted against the harvester's internal resistance is shown in Figure 22. The internal resistance of the EM-VEHs is on the lower side (0.021 to $290 \Omega$ ); however, for the PE-VEHs the internal resistance is relatively high and it ranges from 480 to $200 \mathrm{k} \Omega$. The energy harvesters, for which the lowest $(0.021 \Omega)$ and the highest resistance $(200 \mathrm{k} \Omega)$ are mentioned, are actually not fabricated but only simulations are performed for these devices. The power delivery from the harvester is optimum at impedance matching and therefore it is important to design the energy harvesters in such a way that the harvester's internal impedance is equivalent to the combined impedance of the rectifying circuit and the wireless sensor node.

All of the developed bridge vibration energy harvesters are resonators: that is, these would generate optimum power at resonance condition. However, at off-resonance operation the power production by the resonant energy harvesters is normally on the lower side. Moreover, these energy harvesters have a narrow bandwidth, which is also an issue. Power as a function of resonant frequency is shown in Figure 23. The resonant frequency of all of the bridge energy harvesters is within the frequency band $(1$ to $40 \mathrm{~Hz})$ of the bridge vibrations, except PE-VEH-2 [45] and PE-VEHs [48], whose resonant frequencies are well higher than $40 \mathrm{~Hz}$. For most of the bridge vibration energy harvesters, the resonant frequency is in the range from 1 to $10 \mathrm{~Hz}$.

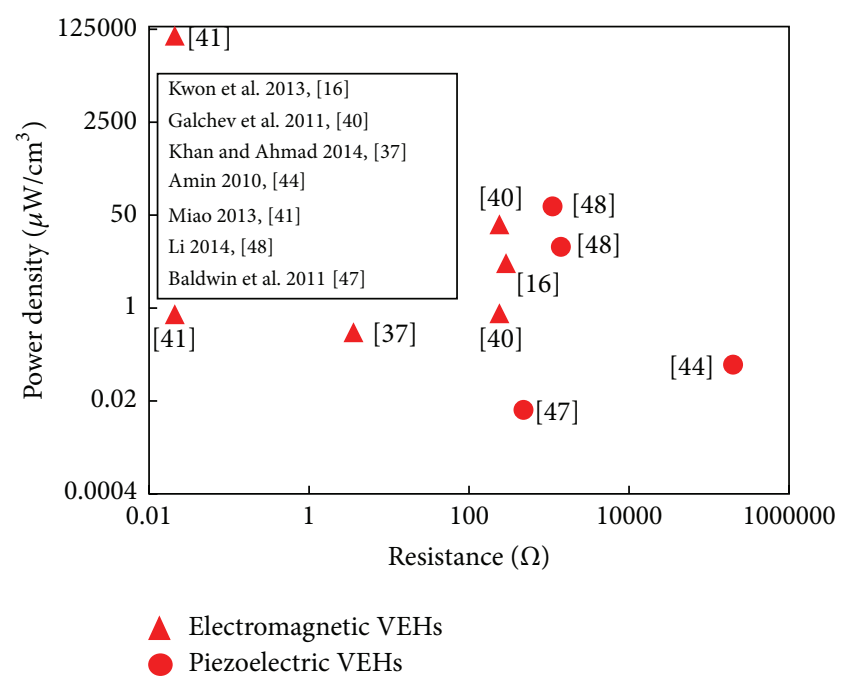

FIGURE 22: Power density versus resistance of different bridge vibration energy harvesters.

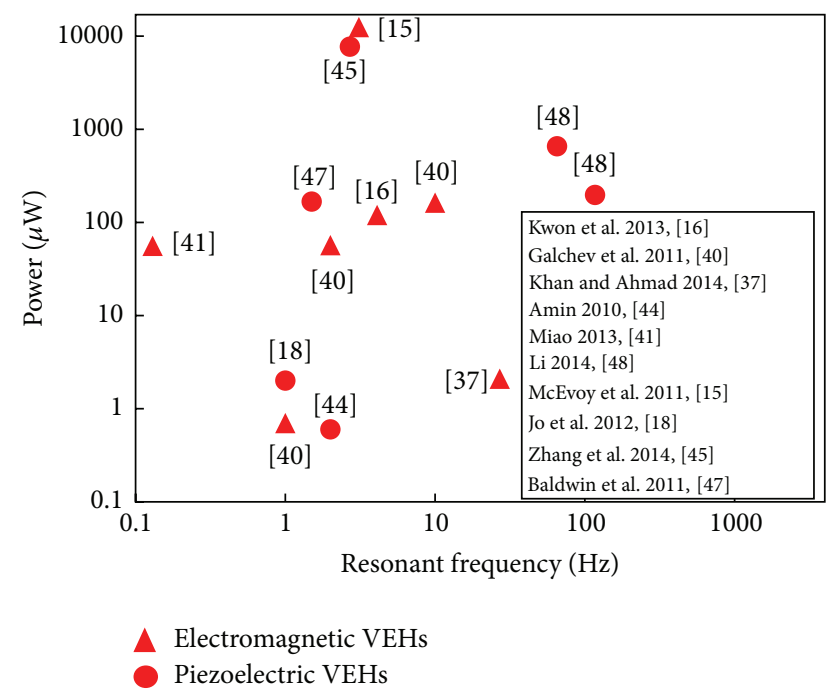

Figure 23: Power developed by the bridge vibration energy harvesters as function of harvester's resonant frequency.

For thorough comparison of the bridge energy harvesters, the power density (PD) and power density per acceleration (PDPA) as function of the harvester's resonant frequency are shown in Figures 24 and 25, respectively. The overall PD of the developed bridge vibration energy harvesters ranges from 0.01 to $9539.5 \mu \mathrm{W} / \mathrm{cm}^{3}$. Among the bridge vibration energy harvesters, $[16,40,48]$ have their PDs on the higher side. The medium range PDs are provided by harvesters $[37,41,44]$, and least most PDs are reported for EM-VEH3 [40] and PE-VEH [47]. Although PE-VEHs [48] seems to produce relatively high $\mathrm{PDs}$, the resonant frequencies (65.2 and $117.1 \mathrm{~Hz}$ ) of these harvesters are way over the frequency band of the bridge vibrations and, therefore, most of the time these would operate at off-resonant frequencies and generate either moderate or low powers. 


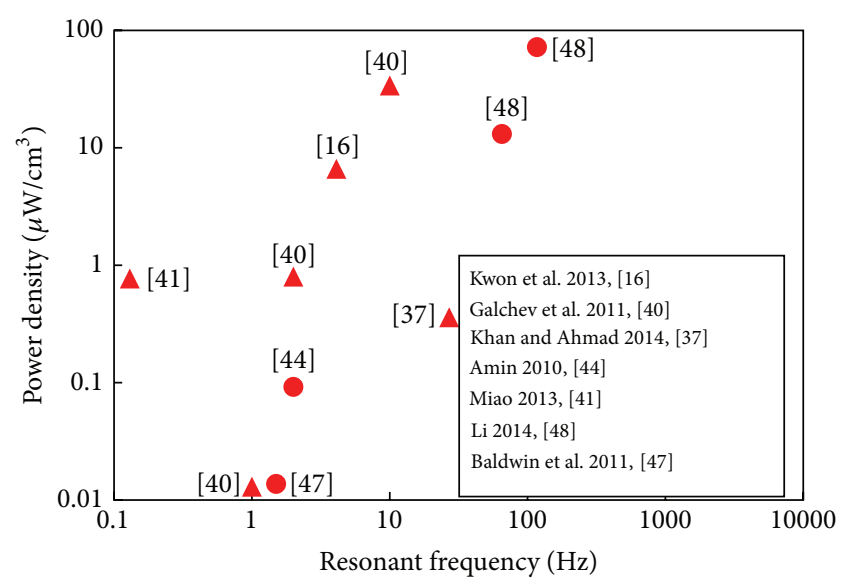

Alectromagnetic VEHs

Piezoelectric VEHs

Figure 24: Power density of bridge vibration energy harvesters verses harvester's resonant frequency.

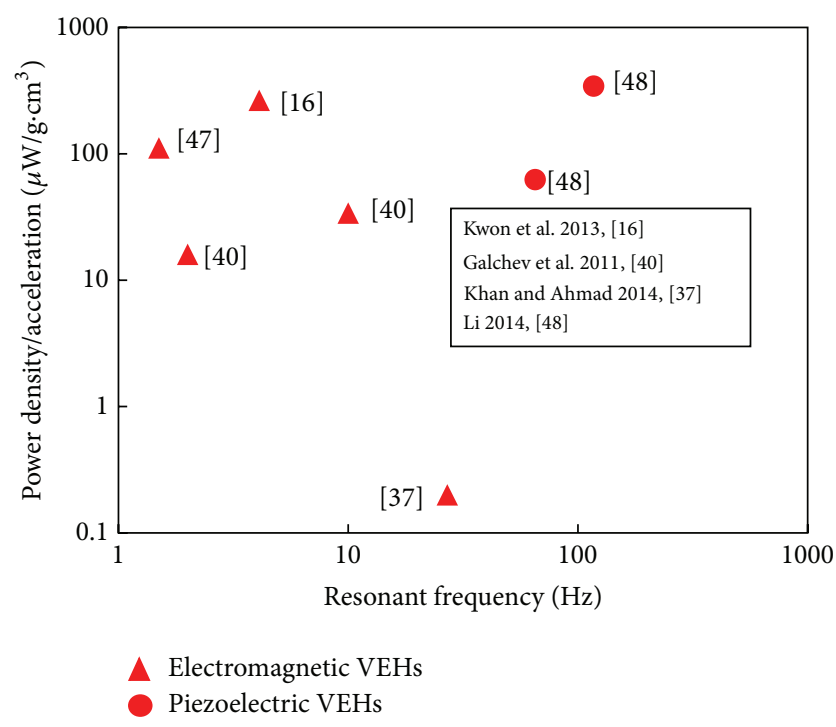

FIGURE 25: Power density per acceleration of bridge vibration energy harvesters verses harvester's resonant frequency.

In Figure 25, when the bridge vibration energy harvesters are compared by PDPA, still harvesters [48] seem promising; however, due to the over the range $(>40 \mathrm{~Hz})$ resonant frequencies, the performance of harvesters reported in [48] will be always under the par. The energy harvesters [16, 40, 47] all have resonant frequencies below $10 \mathrm{~Hz}$ and, moreover, for these devices the PDPA values are on the higher side; therefore, it is expected that these energy harvesters will operate far better than the other reported bridge vibration energy harvesters.

\section{Conclusions}

For autonomous bridge health monitoring system, the wireless acceleration sensor nodes (WASNs) need to be selfpowered nodes. In order to operate autonomously, WASNs require an alternative power source to replace the existing limited shelf life batteries. The energy harvester that extracts the energy from ambient sources (solar energy, thermal energy, acoustic energy, wind energy, and mechanical vibrations) can be integrated with the WASN to autonomously monitor the condition of bridges and civil structures. In bridge surroundings, wind, solar, acoustic, and vibration energies are abundantly available for energy harvesting; however, only bridge vibration has the tendency to be utilized for embedded WASNs applications. This work presents the recent developments and advancements in the field of bridge vibration energy harvesting for autonomous WASNs. So far, two types of bridge vibration energy harvesters are developed and reported in the literature; these are piezoelectric vibration energy harvesters (PE-VEHs) and electromagnetic vibration energy harvesters (EM-VEHs). Due to the ease of inclusion of commercially available piezoelectric material in PE-VEH, it is easy to develop PE-VEHs as compared to EM-VEHs. However, because of high current and power levels generation by EM-VEHs, majority of the reported bridge vibration energy harvesters are based on electromagnetic transduction mechanism. Moreover, the existence of lumped permanent magnet in EM-VEHs attributes to relatively low resonant frequencies of the harvesters, which is highly significant in narrow-band, low frequency bridge's vibration. Till date, for bridge vibrations, the development of electrostatic vibration energy harvesters is not reported in the literature and the possible reason for this is attributed to the usage of initial charging source (battery) and the requirement of the electronic switch circuit during the operation of these energy harvesters.

The overall power generation range for the reported bridge energy harvesters is from 0.7 to $1450000 \mu \mathrm{W}$; however, the resonant frequencies of these energy harvesters fall in the range from 1 to $120 \mathrm{~Hz}$. The power level generated by the developed PE-VEHs is from 0.6 to $7700 \mu \mathrm{W}$ and their resonant frequencies are in the range of $1 \mathrm{~Hz}$ to $120 \mathrm{~Hz}$. The produced EM-VEHs have relatively low resonant frequencies (from $0.13 \mathrm{~Hz}$ to $27 \mathrm{~Hz}$ ) and showed the capability of producing power from $0.7 \mu \mathrm{W}$ to $1450000 \mu \mathrm{W}$. The power generation level of the reported bridge vibration energy harvesters is quite sufficient to operate most of the commercially available wireless sensor nodes discussed in the introduction. Moreover, the resonant frequencies of most of the devised bridge energy harvesters lay in the narrowband (1 to $40 \mathrm{~Hz}$ ) vibrations available at bridge structures.

\section{Conflict of Interests}

The authors declare that there is no conflict of interests regarding the publication of this paper.

\section{References}

[1] A. Hassan and C. Bach, "Improving security connection in wireless sensor networks," International Journal of Innovation and Scientific Research, vol. 2, no. 2, pp. 301-307, 2014. 
[2] Q. I. Ali, "Simulation framework of wireless sensor network (WSN) using matlab/simulink software," 2012, http://cdn .intechopen.com/pdfs-wm/39337.pdf.

[3] K. Sohrabi, J. Gao, V. Ailawadhi, and G. J. Pottie, "Protocols for self-organization of a wireless sensor network," IEEE Personal Communications, vol. 7, no. 5, pp. 16-27, 2000.

[4] A. R. Khan, "Energy efficient protocol design issues in wireless sensor networks," Journal of Information \& Communication Technology, vol. 4, no. 1, pp. 12-18, 2010.

[5] N. Kaur, V. Walia, and R. Malhotra, "Activation matrix oriented base station implementation for energy optimization in wireless sensor networks," International Journal of Computing and Corporate Research, vol. 4, no. 4, 2014.

[6] M. Enckell, Lessons learned in structural health monitoring of bridges using advanced sensor technology [Ph.D. thesis], Division of Structural Engineering and Bridges, Department of Civil and Architectural Engineering, Royal Institute of Technology (KTH), Stockholm, Sweden, 2011.

[7] H. Sohn, C. R. Farrar, F. M. Hemez et al., "A review of structural health monitoring literature: 1996-2001," Report LA-13976-MS, Los Alamos National Laboratory, Los Alamos, NM, USA, 2004, https://institute.lanl.gov/ei/shm/pubs/LA_13976_MSa.pdf.

[8] J. A. Rice, K. Mechitov, S.-H. Sim et al., "Flexible smart sensor framework for autonomous structural health monitoring," Smart Structures and Systems, vol. 6, no. 5-6, pp. 423-438, 2010.

[9] Y. Fujino, D. M. Siringoringo, T. Nagayama, and D. Su, "Control, simulation and monitoring of bridge vibration-Japan's recent development and practice," in Proceedings of the IABSE-JSCE Joint Conference on Advances in Bridge Engineering-II, pp. 6174, Dhaka, Bangladesh, August 2010.

[10] J. Kala, V. Salajka, and P. Hradil, "Footbridge response on single pedestrian induced vibration analysis," World Academy of Science, Engineering and Technology, vol. 3, no. 2, pp. 548-559, 2009.

[11] F. Neitzel, B. Resnik, S. Weisbrich, and A. Friedrich, "Vibration monitoring of bridges," Reports on Geodesy, vol. 1, no. 90, pp. 331-340, 2011.

[12] T. Galchev, J. McCullagh, R. L. Peterson, and K. Najafi, "A vibration harvesting system for bridge health monitoring applications," in Proceedings of the 10th International Workshop on Micro and Nanotechnology for Power Generation and Energy Conversion Applications (PowerMEMS '10), pp. 179-182, Belgium, Leuven, Belgium, November-December 2010.

[13] A. M. Abdel-Ghaffar and R. H. Scanlan, "Ambient vibration studies of golden gate bridge: I. Suspended structure," Journal of Engineering Mechanics, vol. 111, no. 4, pp. 463-482, 1985.

[14] E. Sazonov, H. Li, D. Curry, and P. Pillay, "Self-powered sensors for monitoring of highway bridges," IEEE Sensors Journal, vol. 9, no. 11, pp. 1422-1429, 2009.

[15] T. McEvoy, E. Dierks, J. Weaver et al., "Developing innovative energy harvesting approaches for infrastructure health monitoring systems," in Proceedings of the 37th Design Automation Conference, Parts A and B, pp. 325-339, Washington, DC, USA, August 2011.

[16] S.-D. Kwon, J. Park, and K. Law, "Electromagnetic energy harvester with repulsively stacked multilayer magnets for low frequency vibrations," Smart Materials and Structures, vol. 22, no. 5, Article ID 055007, 2013.

[17] L. Zhang, X. Yan, and X. Yang, "Vehicle-bridge coupled vibration response study of Huanghe cable-stayed bridge due to multiple vehicles parallel with high speed," in Proceedings of the
International Conference on Mechanic Automation and Control Engineering (MACE '10), pp. 1134-1137, Wuhan, China, June 2010.

[18] B. Jo, Y. Lee, G. Yun, C. Park, and J. Kim, "Vibration-induced energy harvesting for green technology," in Proceedings of the International Conference on Chemical, Environment and Civil Engineering (ICCECE '12), pp. 167-170, Manila, Philippines, November 2012.

[19] C. E. Dierks, Design of an electromagnetic vibration energy harvester for structural health monitoring of bridges employing wireless sensor networks [M.S. thesis], Department of Mechanical Engineering, University of Texas at Austin, Austin, Tex, USA, 2011.

[20] S. Boisseau, G. Despesse, T. Ricart, E. Defay, and A. Sylvestre, "Cantilever-based electret energy harvesters," Smart Materials and Structures, vol. 20, no. 10, Article ID 105013, 2011.

[21] D. Spreemann, B. Folkmer, D. Mintenbeck, and Y. Manoli, "Novel non-resonant vibration transducer for energy harvesting," in Proceedings of the International Workshop on Micro and Nanotechnology for Power Generation and Energy Conversion Applications (PowerMEMS '05), pp. 144-146, Tokyo, Japan, November 2005.

[22] Y. B. Jeon, R. Sood, J.-H. Jeong, and S.-G. Kim, "MEMS power generator with transverse mode thin film PZT," Sensors and Actuators A, vol. 122, no. 1, pp. 16-22, 2005.

[23] P. D. Mitcheson, P. Miao, B. H. Stark, E. M. Yeatman, A. S. Holmes, and T. C. Green, "MEMS electrostatic micropower generator for low frequency operation," Sensors and Actuators, A: Physical, vol. 115, no. 2-3, pp. 523-529, 2004.

[24] M.-C. Chiu, Y.-C. Chang, L.-J. Yeh, and C.-H. Chung, "Optimal design of a vibration-based electromagnetic energy harvester using a simulated annealing algorithm," Journal of Mechanics, vol. 28, no. 4, pp. 691-700, 2012.

[25] M. Bhanusri, "Design and simulation of unimorph piezoelectric energy harvesting system," in Proceedings of the COMSOL Conference, pp. 1-6, Bangalore, India, November 2013.

[26] M. Rhimi and N. Lajnef, "Tunable energy harvesting from ambient vibrations in civil structures," Journal of Energy Engineering, vol. 138, no. 4, pp. 185-193, 2012.

[27] M. Ericka, D. Vasic, F. Costa, G. Poulin, and S. Tliba, "Energy harvesting from vibration using a piezoelectric membrane," Journal de Physique IV, vol. 128, pp. 187-193, 2005.

[28] C. Eichhorn, R. Tchagsim, N. Wilhelm, F. Goldschmidtboeing, and P. Woias, "A compact piezoelectric energy harvester with a large resonance frequency tuning range," in Proceedings of the 10th International Workshop on Micro and Nanotechnology for Power Generation and Energy Conversion Applications (PowerMEMS '10), pp. 207-210, Leuven, Belgium, December 2010.

[29] P. D. Mitcheson and T. C. Green, "Maximum effectiveness of electrostatic energy harvesters when coupled to interface circuits," IEEE Transactions on Circuits and Systems I: Regular Papers, vol. 59, no. 12, pp. 3098-3111, 2012.

[30] F. Khan, B. Stoeber, and F. Sassani, "Modeling of linear micro electromagnetic energy harvesters with nonuniform magnetic field for sinusoidal vibrations," Microsystem Technologies, vol. 21, no. 3, pp. 683-692, 2014.

[31] F. Khan, F. Sassani, and B. Stoeber, "Copper foil-type vibrationbased electromagnetic energy harvester," Journal of Micromechanics and Microengineering, vol. 20, no. 12, Article ID 125006, 2010. 
[32] F. Khan, F. Sassani, and B. Stoeber, "Nonlinear behaviour of membrane type electromagnetic energy harvester under harmonic and random vibrations," Microsystem Technologies, vol. 20, no. 7, pp. 1323-1335, 2014.

[33] A. R. M. Foisal and G.-S. Chung, "Fabrication and characterization of a low frequency electromagnetic energy harvester," Journal of Semiconductors, vol. 33, no. 7, Article ID 074001, 2012.

[34] L. A. Vandewater and S. D. Moss, "Modelling of a bi-axial vibration energy harvester," Report DSTO TN-1174, Defence Science and Technology Organisation, Canberra, Australia, 2013, http://www.dsto.defence.gov.au/sites/default/files/publications/documents/DSTO-TN-1174.pdf.

[35] S. P. Beeby, R. N. Torah, M. J. Tudor et al., "A micro electromagnetic generator for vibration energy harvesting," Journal of Micromechanics and Microengineering, vol. 17, no. 7, pp. 12571265, 2007.

[36] B. Marinkovic and H. Koser, "Smart sand-a wide bandwidth vibration energy harvesting platform," Applied Physics Letters, vol. 94, no. 10, Article ID 103505, 2009.

[37] F. U. Khan and I. Ahmad, "Vibration-based electromagnetic type energy harvester for bridge monitoring sensor application," in Proceedings of the 10th International Conference on Emerging Technologies (ICET '14), pp. 125-129, Islamabad, Pakistan, December 2014.

[38] C. Peters, J. Handwerker, D. Maurath, and Y. Manoli, "An ultralow-voltage active rectifier for energy harvesting applications," in Proceedings of the IEEE International Symposium on Circuits and Systems (ISCAS '10), pp. 889-892, Paris, France, June 2010.

[39] M.-F. Liu, T.-P. Chang, and D.-Y. Zeng, “The interactive vibration behavior in a suspension bridge system under moving vehicle loads and vertical seismic excitations," Applied Mathematical Modelling, vol. 35, no. 1, pp. 398-411, 2011.

[40] T. Galchev, H. Kim, and K. Najafi, "Micro power generator for harvesting low-frequency and nonperiodic vibrations," Journal of Microelectromechanical Systems, vol. 20, no. 4, pp. 852-866, 2011.

[41] S. Miao, Energy harvesting from wind-induced vibration of suspension bridges [M.S. thesis], Department of Civil and Environmental, Massachusetts Institute of Technology, 2013.

[42] W. A. Shen and S. Zhu, "A dual-function electromagnetic damper for bridge stay cable vibration mitigation and energy harvesting," in Proceedings of the 13th East Asia-Pacific Conference on Structural Engineering and Construction (EASEC '13), Sapporo, Japan, September 2013.

[43] M. Peigney and D. Siegert, "Piezoelectric energy harvesting from traffic-induced bridge vibrations," Smart Materials and Structures, vol. 22, no. 9, Article ID 095019, 2013.

[44] M. H. Amin, Analysis of piezoelectric energy harvesting for bridge health monitoring systems [M.S. thesis], Computational Engineering Centre, School of Engineering, University of Swansea, Wales, UK, 2010.

[45] Y. Zhang, C. S. Cai, and W. Zhang, "Experimental study of a multi-impact energy harvester under low frequency excitations," Smart Materials and Structures, vol. 23, no. 5, Article ID 055002, 2014.

[46] S. F. Ali, M. I. Friswell, and S. Adhikari, "Analysis of energy harvesters for highway bridges," Journal of Intelligent Material Systems and Structures, vol. 22, no. 16, pp. 1929-1938, 2011.
[47] J. D. Baldwin, S. Roswurm, J. Nolan, and L. Holliday, "Energy harvesting on highway bridges," Final Report FHWA-OK-11-01, 2011, http://www.okladot.state.ok.us/hqdiv/ p-r-div/spr-rip/library/reports/rad_spr2-i2224-fy2010-rpt-finalbaldwin.pdf.

[48] J. Li, Structural health monitoring of an in-service highway bridge with uncertainties [Ph.D. thesis], University of Connecticut, Mansfield, Conn, USA, 2014.

[49] S. H. Valluru, Energy harvesting from vibration of a bridge [Master of Science Thesis], University of Tennessee, Knoxville, Tenn, USA, 2007. 


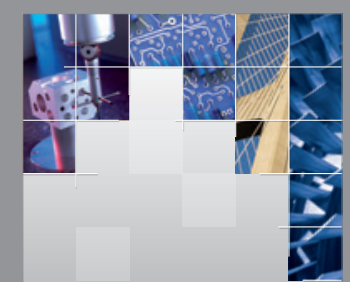

\section{Enfincering}
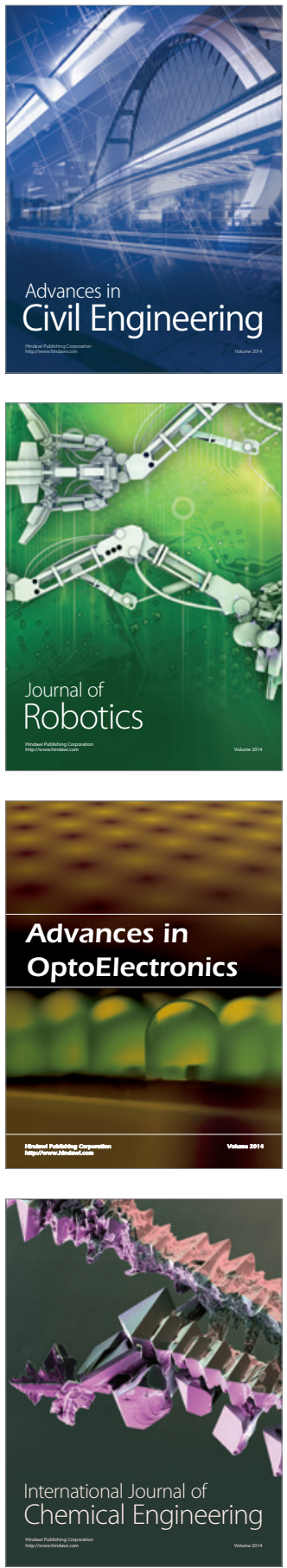

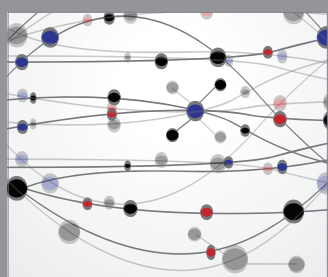

The Scientific World Journal

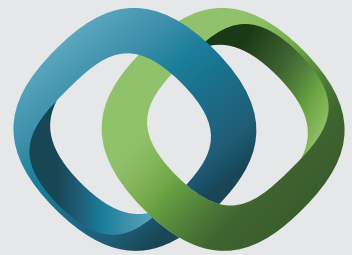

\section{Hindawi}

Submit your manuscripts at

http://www.hindawi.com
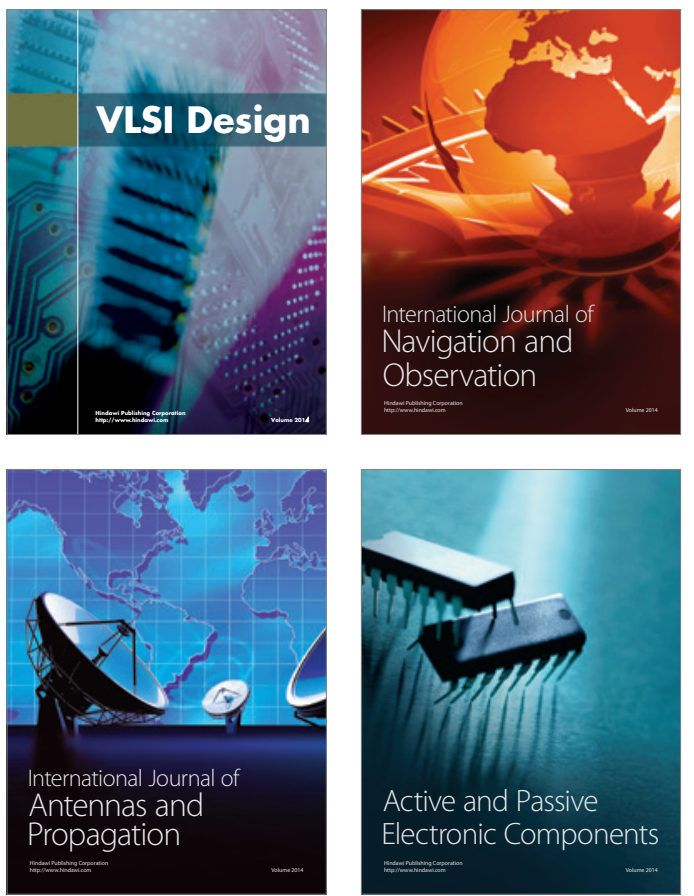
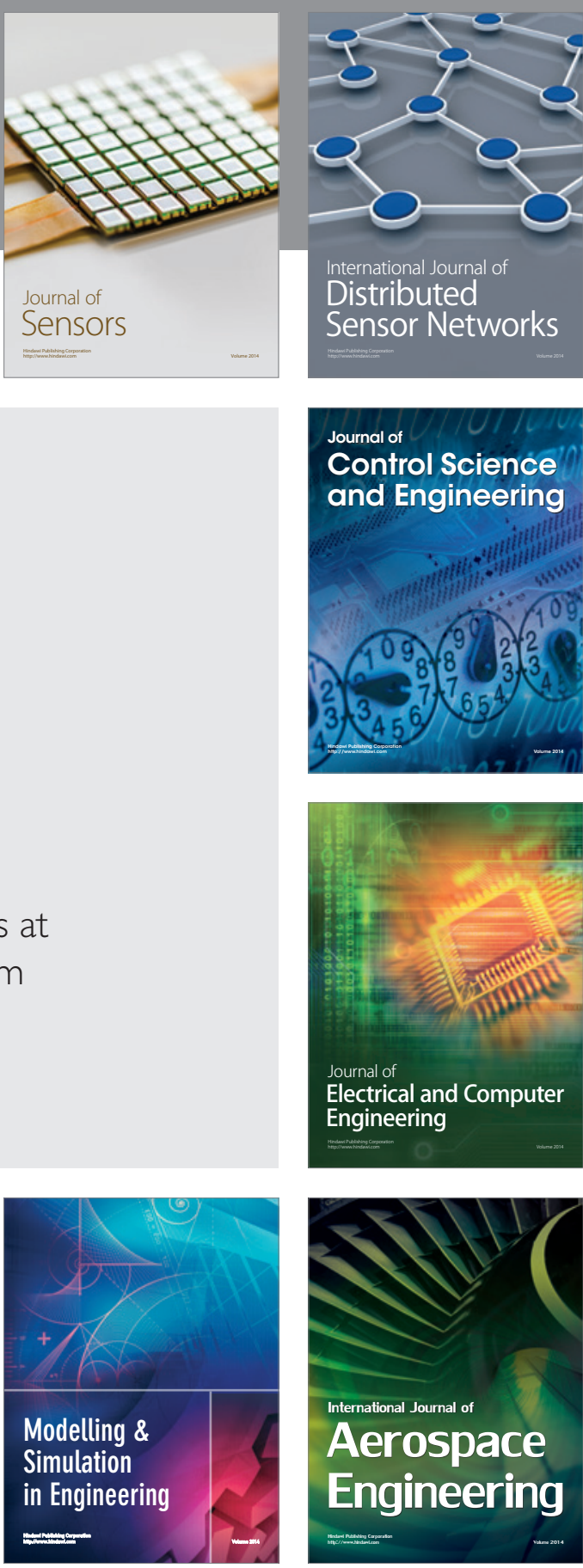

International Journal of

Distributed

Sensor Networks

Journal of

Control Science

and Engineering
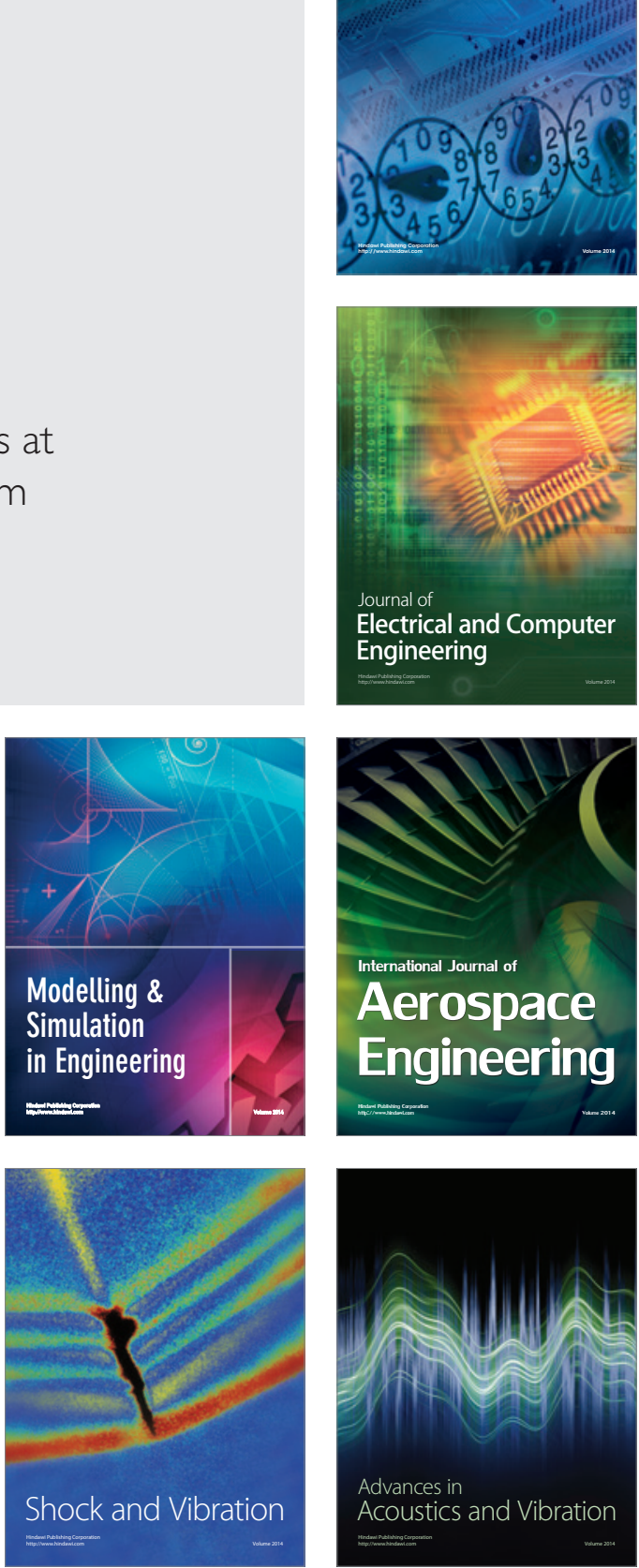